\title{
The Effect of Customer Empowerment on Adherence to Expert Advice
}

\author{
Nuno Camacho ${ }^{1, *}$ \\ Martijn De Jong ${ }^{2}$ \\ Stefan Stremersch ${ }^{3}$ \\ March $30^{\text {th }}, 2014$ \\ To Appear In: \\ International Journal of Research in Marketing, 31(3), June-July, 2014
}

${ }^{1}$ Nuno Camacho (camacho@ese.eur.nl) is Assistant Professor of Marketing at the Erasmus School of Economics, Erasmus University Rotterdam, the Netherlands.

${ }^{2}$ Martijn De Jong (mgdejong@ese.eur.nl) is Professor of Marketing at the Erasmus School of Economics, Erasmus University Rotterdam, the Netherlands.

${ }^{3}$ Stefan Stremersch (stremersch@ese.eur.nl) is Chaired Professor of Marketing and the Desiderius Erasmus Distinguished Chair of Economics, at the Erasmus School of Economics, Erasmus University Rotterdam, the Netherlands, and Professor of Marketing, at IESE Business School, University of Navarra, Spain.

* Corresponding author. Tel.: +31.10.4081303; Fax: +31.10.4089169. Address: Burg. Oudlaan 50, room H15-09, 3062 PA Rotterdam, the Netherlands.

We thank the Marketing Science Institute for financial support. We are also indebted to Bas Donkers, Benedict Dellaert and Gerry Tellis for their insightful comments and suggestions. We also thank participants at the 2010 Marketing Science and 2011 EMAC Conferences and seminar participants at Groningen University, Tilburg University and Católica Lisbon - School of Business and Economics for all their valuable suggestions. The usual disclaimer applies. 


\title{
The Effect of Customer Empowerment on Adherence to Expert Advice
}

\author{
Abstract \\ Customers often receive expert advice related to their health, finances, taxes or legal \\ procedures, to name just a few. A noble stance taken by some is that experts should empower \\ customers to make their own decisions. In this article, we distinguish informational from \\ decisional empowerment and study whether empowerment leads customers to adhere more or \\ less to expert advice. We empirically test our model using a unique dataset involving 11,735 \\ respondents in 17 countries on four continents. In the context of consumer adherence to doctors' \\ therapy advice (patient non-adherence to doctor advice may cost about $\$ 564$ billion globally to \\ the pharmaceutical industry every year), we find that decisional empowerment lowers adherence \\ to expert advice. The effect of informational empowerment varies predictably across cultures and \\ is only universally beneficial when initiated by the customer. These findings have important \\ implications for professional service providers.
}

Keywords: Relationship; services marketing; expert services; professional services; advicetaking, advice-giving, adherence to expert advice; empowerment; delegation; international marketing research; cross-cultural studies; health marketing; consumer behavior. 


\section{Introduction}

Customers often rely on experts, such as accountants, consultants, lawyers and physicians to make complex decisions (Bove \& Johnson, 2006). Expert advice decreases decision complexity (Brehmer \& Hagafors, 1986) and may improve decision quality (Yaniv, 2004). There is a rich literature, in marketing and psychology, on customer-expert interactions. One stream of literature focuses on how experts use customers' input and feedback to update their beliefs and decisions (e.g. Camacho, Donkers, \& Stremersch, 2011; Narayanan \& Manchanda, 2008). For instance, Camacho, Donkers and Stremersch (2011) show that, when learning about a new drug, physicians place more emphasis on feedback from patients who switch to alternative treatments than on feedback from patients who continue their therapy. A second stream of literature focuses on expert advice and customer adherence to such advice (Bonaccio \& Dalal, 2006; Bowman, Heilman, \& Seetharaman, 2004; Fitzsimons \& Lehmann, 2004; Schwartz, Luce \& Ariely, 2011; Tost, Gino, \& Larrick, 2012; Usta \& Häubl, 2011). The present paper focuses on the effects of customer empowerment during an advising interaction on customer adherence to expert advice.

In a typical customer-expert interaction, a customer receives an advice from the expert and subsequently decides whether to adhere to such advice ${ }^{1}$. A robust finding from this literature is that people do not sufficiently adhere to expert advice (Bonaccio \& Dalal, 2006). The traditional view of customer-expert interactions is that the expert should choose a particular course of action on behalf of the customer (e.g. "I would advise you to do X", see Bonnacio \& Dalal, 2006, p.128), a decision-making style we call "paternalistic" (e.g. Charles, Gafni \&

\footnotetext{
${ }^{1}$ We assume a setting where the customer seeks the advice of a single expert and that customer adherence to the expert's advice improves decision quality for the customer. This assumption builds upon the advice-taking literature (Bonaccio \& Dalal, 2006; Yaniv \& Kleinberger, 2000; Yaniv, 2004).
} 
Wheelan, 1999). For example, a paternalistic lawyer-client interaction proceeds with a client exposing a legal problem to her lawyer who then recommends a particular course of action to the client (Macfarlane, 2008). The lawyer then expects the client to follow her advice to maximize chances of successful litigation.

This traditional view of customer-expert decision-making stands in sharp contrast to the increasing influence or empowerment of the customer (Camacho, 2014; Camacho, Landsman, \& Stremersch, 2010; Fuchs, Prandelli \& Schreier, 2010; Macfarlane, 2008; Rapp et al. 2006). Empowerment refers to strategies or mechanisms that equip people with sufficient knowledge and autonomy to allow them to exert control over a certain decision (Ozer \& Bandura, 1990). Empowerment occurs when, instead of merely sharing diagnostic information - i.e. information that allows the expert to understand the customer's problem - the expert and the customer discuss additional solution-relevant information. That is, information about alternative courses of action (e.g. "there are two possible courses of action: option $\mathrm{X}$ and option $\mathrm{Y}$ "), their pros and cons (e.g. "the downside of option $\mathrm{X}$ is...") or their fit with the customer's own preferences ("I believe option Y may fit you well because...”). Finally, empowerment also occurs when instead of recommending a single course of action the expert concludes the interaction by leaving the final choice of a course of action in the hands of the customer (e.g. "we discussed options X and Y, please make your informed choice").

Therefore, we distinguish between two different forms of customer empowerment. Informational empowerment occurs when the customer and the expert share solution-relevant information. Decisional empowerment occurs when the expert leaves the final decision to the 
customer $^{2}$. We organize customer-expert decision-making models, according to these dimensions of empowerment, which is new to the literature.

Recent views suggest that customer empowerment leads to better outcomes because it satisfies customers' need for autonomy and self-esteem (Usta \& Häubl, 2011). One of these accredited outcomes is increased customer adherence to expert advice (Loh et al., 2007; Macfarlane, 2008). However, despite an increasing number of advocates of customer empowerment in customer-expert interactions (Epstein, Alper \& Quill, 2004; Macfarlane, 2008), there is limited empirical research on how customer empowerment influences customer adherence to expert advice.

The present paper develops theoretical expectations on the relationship between empowerment and adherence, grounded in two theoretical traditions: dual models of information processing (Chaiken, 1980; Petty, \& Cacioppo, 1986) and customer overconfidence (See et al., 2011; Tost, Gino, \& Larrick, 2012; Yaniv \& Kleinberger, 2000). Connected to these two theoretical mechanisms, we distinguish between two different forms of non-adherence to expert advice, namely unintentional and reasoned non-adherence. Unintentional non-adherence occurs when a customer inadvertently fails to follow the expert's advice (e.g. due to forgetfulness or misunderstanding of the advice). Reasoned non-adherence occurs when a customer deliberately decides to deviate from the expert's advice.

We challenge the view that customer empowerment may only increase adherence to expert advice and provide rich empirical evidence in support of this view. We argue that

\footnotetext{
${ }^{2}$ In line with the advice-taking literature (see e.g. Bonaccio \& Dalal, 2006), the expert advisor merely provides a recommendation, so effectively the final decision always lies with the customer. Even if the customer has the legal right and responsibility to make the final decision, the expert can still decide to advise a single course of action.
} 
empowerment may decrease, rather than increase, adherence for two reasons. First, informational empowerment, when not explicitly requested by the customer, may increase the cognitive and emotional burden for customers (Quill \& Brody, 1996), and impair information processing, which results in higher unintentional non-adherence. Similarly, decisional empowerment may magnify the cognitive and emotional costs of the decision task (Botti \& McGill, 2011), resulting in worse information processing and higher unintentional non-adherence.

Second, decisional empowerment, and to a lesser extent unrequested informational empowerment, may trigger customer overconfidence. Customer overconfidence may increase both unintentional and reasoned non-adherence. On the one hand, overconfident customers tend to listen less carefully to expert advice (Tost, Gino, \& Larrick, 2012), which increases unintentional non-adherence. On the other hand, overconfident customers tend to egocentrically discount the expert's advice (See et al. 2011, Yaniv, 2004), which increases reasoned nonadherence.

Using a multi-sample Bayesian structural equation model, we show that decisional empowerment is associated with higher unintentional and reasoned non-adherence to expert advice and that informational empowerment is only able to reduce unintentional and reasoned non-adherence when the customer explicitly requests the exchange of additional solutionrelevant information. We empirically validate our expectations in the highly relevant domain of healthcare decisions. Consumer non-adherence to doctor advice contributes to disease progression and increased mortality rates, resulting in annual direct and indirect healthcare costs 
of at least \$290 billion in the U.S. alone (New England Healthcare Institute, 2009) and lost revenue for pharmaceutical firms of $\$ 564$ billion a year globally (Forissier \& Firlik, 2012) ${ }^{3}$.

Our sample includes 11,735 respondents in 17 countries on four continents. To the best of our knowledge, this is by far the largest and geographically most diverse test of the relationship between customer empowerment and adherence to date. Prior empirical research on the relationship between empowerment and adherence to expert advice has focused on the U.S. or a selected set of Western nations, while customers' reaction to empowerment may be vastly different across cultures (Botti, Orfali \& Iyengar, 2009; Charles et al., 2006).

We build upon Schwartz's (1994) cultural values theory, to explain systematic crosscountry differences in the relationship between customer empowerment and adherence to expert advice. Our analyses revealed that, in line with our expectations, culture matters. We find that culture moderates the effects of decisional empowerment and, to a lesser extent, of informational empowerment on non-adherence in systematic and predictable ways. These findings have important implications for marketers and policy makers.

\section{Theoretical Background: Customer Empowerment and Adherence to Expert Advice}

The expert advice literature typically distinguishes between advice-giving and advice-taking (Bonaccio \& Dalal, 2006; Yaniv, 2004). We first organize advice-giving styles according to customer empowerment. Next, we discuss advice-taking, which, in our context, is the customer's decision to adhere or deviate from the expert's advice.

\footnotetext{
${ }^{3}$ See https://www.adherence564.com/.
} 


\subsection{Organizing Advice-Giving Styles According to Customer Empowerment}

Figure 1 organizes different advice-giving styles, according to informational empowerment, through expert facilitation (x-axis) or customer initiative (y-axis), and decisional empowerment (the z-axis). Expert facilitation of informational empowerment happens when the expert proactively exchanges solution-relevant information with the customer (i.e. takes the initiative of sharing solution-relevant information even if it is not requested by the customer). Customerinitiated informational empowerment happens when the customer requests solution-relevant information from the expert. Under decisional empowerment, the customer retains autonomy over the decision, which is the opposite of decision delegation by the customer to the expert (see Usta \& Häubl, 2011).

The advice-giving styles at the bottom of Figure 1 are characterized by low decisional empowerment (i.e. choice delegation), while those at the top are characterized by high decisional empowerment (i.e. choice autonomy).

--- Insert Figure 1 around here ---

In the bottom left of the graph, we depict the traditional paternalistic model which is characterized by low decisional empowerment and by low informational empowerment (Charles, Gafni \& Wheelan, 1999). In a paternalistic model, the expert decides on behalf of the customer in a paternalistic manner and hence only needs to exchange the information needed to identify and understand the customer's problem (diagnostic information). In informed delegation models, customers and experts also exchange solution-relevant information. Conditional on the information collected, the expert then applies her knowledge to choose an option that maximizes the customer's utility (Phelps, 1992). 
At the top of Figure 1, we depict consumerist and informed autonomy models. In consumerist models (Coulter, 1999), the customer demands that the expert helps her execute a self-chosen course of action and there is no exchange of solution-relevant information. Examples of consumerism include requests for a specific litigation strategy by clients to their lawyers (Macfarlane, 2008) and branded request by patients to their doctors (Venkataraman \& Stremersch, 2007), a phenomenon that has steadily increased in recent years (Stremersch, Landsman, \& Venkataraman, 2013). To the extent that the customer takes initiative in exchanging solution-relevant information during her interaction with the expert, consumerism can yield customer-driven informed autonomy (Charles, Gafni \& Whelan, 1999). In the expertdriven informed autonomy model (Quill \& Brody, 1996), the expert facilitates the exchange of solution-relevant information, but leaves the final choice of a course of action to the customer.

\subsection{Advice-Taking: Customer Adherence to Expert Advice}

We conceptualize adherence to expert advice as the propensity of a customer to follow an expert's advice (Bonaccio \& Dalal, 2006; DiMatteo et al., 1993). Adherence to expert advice requires an effortful commitment of the customer to implement the behaviors recommended by the expert during the advising interaction. If customers have difficulty to understand or recall some of the information transmitted by the expert (e.g., the different steps a tax advisor recommended his client to minimize her tax payments), they may unintentionally non-adhere to the advice. If customers do not accept and deliberately deviate from the expert's advice (and rely more on their own opinion than on the expert's opinion), we speak of reasoned non-adherence (Bonaccio \& Dalal, 2006; Yaniv \& Kleinberger, 2000). 


\section{Hypotheses Development}

In developing hypotheses about the effects of customer empowerment on adherence to expert advice, we rely on two key psychological mechanisms: (1) dual models of information processing (Chaiken, 1980; Petty, \& Cacioppo, 1986) and (2) customer overconfidence (See et al., 2011; Tost, Gino, \& Larrick, 2012; Yaniv \& Kleinberger, 2000).

Dual models of information processing, such as the heuristic systematic model (HSM; Chaiken, 1980; Chaiken, Liberman, \& Eagly, 1989) and the elaboration likelihood model (ELM; Petty \& Cacioppo, 1986) posit that customers possibly engage in two modes of information processing, which involve different levels of thought and cognitive effort. Heuristic (or peripheral) processing is relatively effortless and quick while systematic (or central) processing requires customers to devote more cognitive resources to process information. A good example, in a healthcare context, is provided by Steginga and Occhipinti (2004) who show, for patients with prostate cancer, that customers may either use an expert opinion heuristic (e.g. "experts can be trusted", p.574) or more systematic information processing strategies (e.g. weighing all pros and cons of different recommended options). For these reasons, dual-process models have special relevance for the effects of informational empowerment on unintentional non-adherence.

Recent research in social psychology suggests that empowerment may lead people to feel more powerful in a relationship and become overconfident about their abilities (See et al., 2011). Overconfident customers tend to overweight their own knowledge and opinions and therefore: (i) listen less carefully to expert advice (Tost, Gino, \& Larrick, 2012) and (ii) egocentrically

discount expert advice (Bonaccio \& Dalal, 2006; See et al. 2011, Yaniv, 2004). Moreover, when given power in a certain decision task, people tend to generalize their overconfidence to tasks outside the original scope of empowerment (Weitlauf et al., 2001). Hence, customer 
overconfidence has special relevance for the effects of decisional empowerment on nonadherence and for the effects of informational empowerment on reasoned non-adherence.

\subsection{Expert Facilitation of Informational Empowerment and Customer Non-Adherence}

Expert facilitation occurs when an expert proactively exchanges solution-relevant information with the customer during an advising interaction (e.g. a doctor asks a child whether she likes strawberries or cherries to decide on a drug's flavor to prescribe, or a lawyer discusses with a client which expert witness to appoint in a patent litigation case). Experts often exchange unrequested solution-relevant information with customers in order to increase the customer's involvement and responsibility in a given decision-making task (Epstein, Alper \& Quill, 2004). Dual-process models predict that elevated responsibility increases task importance and thus motivates customers to use systematic, rather than heuristic, information processing (Bohner et al. 1995; Chaiken, 1980). However, systematic processing of unrequested pieces of information may increase customers' cognitive and emotional burden and eventually obscure other relevant pieces of information (Epstein, Korones, \& Quill, 2010).

Thus, when compared with a paternalistic model, expert facilitation of informational empowerment requires the customer to systematically process additional solution-relevant information. Such additional information will compete, in the customer's memory, with other key pieces of information in the expert's advice (e.g. dosing instructions in a patient-physician interaction or advice on specific litigation steps in a lawyer-client interaction), making the latter less salient and the advice harder to recall ${ }^{4}$ (Raaijmakers \& Shiffrin, 1992), as compared to a

\footnotetext{
${ }^{4}$ Experts may write down their advice to facilitate customer recall. Still, customers often unintentionally deviate from written advice. Morris and Halperin (1979), for example, find that written doctor advice increases adherence to short-term, but not long-term, therapy advice and only if the written advice is "sufficiently attractive, easy-to-read,
} 
paternalistic interaction. Forgetting, in turn, is one of the key reasons why customers do not adhere to expert advice (Osterberg \& Blaschke, 2005). Thus, we expect that:

H1: Expert facilitation of informational empowerment increases unintentional non-adherence.

Customers often suffer, in their relationship with advisors, from "egocentric bias", i.e. from a tendency to overweight their own opinion and egocentrically discount the expert's advice (Bonnacio \& Dalal, 2006; Yaniv \& Kleinberger, 2000). This means that even when a customer accepts that the expert's advice is correct, she may still depart from this advice and maintain her own prior attitudes and beliefs, resulting in reasoned non-adherence (Bonnacio \& Dalal, 2006). Expert facilitation of informational empowerment may increase this tendency. When compared with a paternalistic model, expert facilitation of informational empowerment may elevate customers' perceived power in the customer-expert relationship, i.e. the belief in their own ability to decide and control the problem being discussed (Tost, Gino, \& Larrick, 2012). Customers with an elevated perceived power tend to become overconfident, which leads them to place more weight in their own beliefs and less weight in the expert's advice (Bonaccio \& Dalal, 2006; See et al. 2011, Yaniv, 2004). Therefore, expert facilitation of informational empowerment may trigger customers to egocentrically discount the expert' advice more than a paternalistic customer-expert interaction. Therefore, we hypothesize the following:

H2: Expert facilitation of informational empowerment increases reasoned non-adherence. 


\subsection{Customer-Initiated Informational Empowerment and Customer Non-Adherence}

Customer-initiated informational empowerment results in the discussion of solution-relevant information that the customer finds self-relevant and meaningful. Prior research in dual-process models shows that high self-relevance triggers systematic information processing (Chaiken, 1980). Systematic processing of self-relevant information should increase customers' motivation to carefully listen to the advice (Ryan \& Deci, 2000), which, in turn, facilitates understanding and recall of the information exchanged. For instance, Kreuter et al. (1999) show that cognitive elaboration focused on self-relevant information facilitates understanding and future recall of health-related advice. Similarly, Brug et al. (1996) find that people who receive nutrition advice customized to their personal dietary behavior perceive such advice as self-relevant and adhere more to advice than people who receive non-tailored advice. In line with this logic, Abele and Gendolla (2007) show that active exercisers process health information focusing on physical exercise more deeply, and recall it better, than non-active exercisers. Thus, we expect that:

H3: Customer-initiated informational empowerment decreases unintentional non-adherence.

Customer-initiated informational empowerment may also affect reasoned non-adherence. When compared with a paternalistic model, customer-initiated informational empowerment may affect the distribution of perceived power between the customer and the expert in different ways. The effect thereof on reasoned non-adherence is unclear. On the one hand, it may be possible that the customer gains power in the customer-expert relationship. This happens if the customer discovers, in the expert's response to her request for solution-relevant information, evidence that contradicts the expert's advice (Chaiken, Liberman, \& Eagly, 1989). Contradictory information enables the customer to challenge the validity of the expert advice, which may increase the customer's perceived power relative to the expert. 
On the other hand, it may also be conceivable that the expert gains power in the customer-expert relationship. For instance, the expert may push back the customer's initiative and refuse to discuss solution-relevant information. When compared with a paternalistic interaction, an expert's refusal to respond to a customer's requests for additional information avoids the increase in perceived power, and subsequent customer overconfidence, discussed above (Izraeli \& Jick, 1986). Alternatively, the expert may, through skillfully answering the questions posed by the customer, increase her expert status and undermine customer overconfidence.

Hence, when compared to a paternalistic interaction, customer-initiated informational empowerment may increase, or decrease, the customer's tendency to egocentrically discount the expert's advice (Yaniv \& Kleinberger, 2000). Given these conflicting expectations, the ultimate effect of customer-initiated informational empowerment on reasoned non-adherence will depend on which of these two forces dominates and is, thus, an empirical question.

\subsection{Decisional Empowerment and Therapy Non-Adherence}

Decisional empowerment may increase unintentional non-adherence in two main ways. First, decisional empowerment may trigger customer overconfidence and worse information processing. Decisional empowerment allows customers to feel in control of their decisions, and increases their power in the customer-expert relationship (Botti \& McGill, 2011). As discussed above, power may trigger overconfidence (See et al., 2011). Hence, when compared with a paternalistic model, decisional empowerment should lead customers to overestimate the accuracy of their beliefs and opinions, which leads them to listen and process the expert advice less carefully (Tost, Gino, \& Larrick, 2012). Less careful processing of the advice increases the likelihood that the customer forgets components of the advice. 
Second, decisional empowerment increases the customer's responsibility in decisionmaking, potentially magnifying the emotional and cognitive costs of the decision task (Botti \& McGill, 2011; Botti, Orfali \& Iyengar, 2009). These effects may increase customer anxiety (Botti, Orfali \& Iyengar, 2009), which, in turn, has been shown to impair information processing (Sengupta \& Johar, 2001). Consequently, decisional empowerment impairs the quality of the customer-expert communication and reduces the salience of the expert's advice making it harder to recall later. We thus hypothesize:

H4: Decisional empowerment increases unintentional non-adherence.

Decisional empowerment may also increase the likelihood of reasoned non-adherence. When compared with expert facilitation of informational empowerment, decisional empowerment represents a stronger departure from the traditional paternalistic customer-expert relationship (Charles, Gafni \& Whelan, 1999; Quill \& Brody, 1996). In addition, decisional empowerment entails patient participation in the decision-making without necessarily allowing the customer to learn more about the problem under discussion. Hence, as discussed above, decisional empowerment may elevate customer power and trigger overconfidence, which should lead customers to place less weight on the expert's opinion and egocentrically discount the expert advice (See et al., 2011; Yaniv \& Kleinberger, 2000).

In addition, overconfident customers tend to generalize their self-efficacy perceptions from a focal decision domain to decision domains outside the original scope of empowerment (Weitlauf et al., 2001). Accordingly, decisional empowerment during an advising interaction (e.g. participating in the choice of one out of several alternative courses of action) may lead customers to become overconfident about their capacity to decide when to alter or stop their adherence to expert advice, increasing reasoned non-adherence. In the words of Bowman, 
Heilman and Seetharaman (2004), in the context of physicians empowering patients to make their own treatment choices, the "perception of empowerment and control should persist such that the consumer also believes that he or she is capable of changing dosage or stopping usage altogether without physician consultation" (p. 325). Therefore, we hypothesize that:

H5: Decisional empowerment increases reasoned non-adherence.

\subsection{Cultural Effects}

Behavioral responses to customer empowerment may be vastly different across different national cultures (Charles et al., 2006). In particular, we expect national-cultural values to shape expectations about the role of experts and to trigger positive or negative social reinforcement mechanisms that moderate the effects of customer empowerment on non-adherence. This fits the tradition in international marketing of considering national-cultural values as moderators of customer behavior (Burgess \& Steenkamp, 2006; Steenkamp \& De Jong, 2010; Steenkamp \& Geyskens, 2013; Stremersch \& Tellis, 2004; Stremersch \& Lemmens, 2009; Tellis, Stremersch, \& Yin, 2003; Van den Bulte \& Stremersch, 2004; van Everdingen, Fok, \& Stremersch, 2009).

We adopt Schwartz's (1994) framework of national-cultural values, instead of alternative frameworks of Hofstede, Inglehart and Baker, or Triandis (see Vinken, Soeters \& Ester, 2004, for an overview), for three key reasons. First, Schwartz derived his cultural dimensions from his individual-level theory of human value priorities (Schwartz, 1992), which is one of the most widely validated theories in social sciences (Schwartz et al., 2001). For this reason, Schwartz's (1994) cultural framework is conceptually the most pure among existing theories of nationalcultural values (Burgess \& Steenkamp, 2006; Bond et al., 2004).

Second, this framework is robust in terms of its measurement properties. The different value dimensions in this framework form an integrated and interdependent system, in contrast to 
other frameworks in which cultural dimensions are orthogonal to each other (e.g. Hofstede, 2001; Inglehart \& Baker, 2000). The cultural dimensions in Schwartz's (1994) framework are also clearly defined and operationalized a priori, in contrast to other frameworks that, ex post, infer cultural dimensions from correlations among diverse items and exploratory analyses (e.g. Inglehart \& Baker, 2000).

Third, Schwartz's values theory explicitly addresses the distinction between the individual and nation-cultural levels of analysis. Scholars have recently challenged the notion of culture as a set of meanings and principles shared by most members of a certain society (Fischer \& Schwartz, 2011). In contrast with other cultural theories, Schwartz's conception of cultural values as a normative system that is external to individuals (but underlies the functioning of societal institutions) does not assume a high level of within-country consensus (Fischer \& Schwartz, 2011; Schwartz, 2009, 2011).

All the reasons above suggest that Schwartz's framework fits well with the topic of customer empowerment. Its bipolar dimensions capture opposing choices to three critical needs that confront most societies (Burgess \& Steenkamp, 2006; Schwartz, 2006). The first dimension relates to the need to organize the relations between the individual and the group. Highautonomy cultures emphasize individuality, independence and self-expression. Affective autonomy cultures encourage individuals to act according to their own preferences. Intellectual autonomy cultures encourage individuals to develop their own opinions. In contrast, highembeddedness cultures emphasize social relationships, group identification, respect for tradition and obedience.

The second dimension represents the need to guarantee responsible behaviors that protect the social fabric. There are two opposing ways to reach this goal. Egalitarian cultures tend to 
instill socially responsible behavior by inducing people to see each other as moral equals and emphasizing equality and equal distribution of power. People in such societies tend to internalize cooperation and concern with others as a life-guiding principle. Hierarchical cultures rely on an unequal distribution of power and roles as a legitimate mechanism to guarantee behaviors that protect the social fabric.

The third dimension relates to the need to manage the relations of people to society and the environment. High-mastery cultures emphasize success, daring and competence. Highharmonious cultures emphasize the need to fit into the social and natural world and the importance of behaving in a way that is congruent with the social and natural environment.

We expect culture to intensify or attenuate our hypothesized relationships for the effects of customer empowerment on non-adherence in three ways. First, as customers in high intellectual autonomy cultures are more inclined to pursue their own opinions independently, as compared with customers in low intellectual autonomy cultures (Schwartz, 2006), they should be more likely to become overconfident when exposed to expert facilitation of informational empowerment or decisional empowerment. In high-embeddedness cultures, in contrast, customers are less likely to engage in actions that may disrupt traditional roles and in-group solidarity (Burgess \& Steenkamp, 2006). Thus, we expect customers in societies that emphasize embeddedness to be less likely to discount the expert's advice, in order to avoid disrupting the customer-expert relationship, as compared to customers in societies that emphasize autonomy.

Second, when compared with customers in egalitarian societies, customers in hierarchical societies should be more likely to ascribe power to the expert because of her presumed access to superior knowledge and information (Burgess \& Steenkamp, 2006). When customers ascribe more power to an expert, they are more likely to invest additional effort to understand and recall 
the expert's advice (Tost, Gino, \& Larrick, 2011). We also expect customers in hierarchical societies to be less likely to become overconfident and more likely to "comply with the obligations and rules attached to their roles and status" (Burgess \& Steenkamp, 2006, p. 343). Hence, we expect the detrimental effects of customer empowerment (especially of expert facilitation of informational empowerment and decisional empowerment) on non-adherence to be less pronounced in hierarchical cultures.

Finally, we expect customers in high-mastery societies - such as the U.S. - to be more likely to perceive customer empowerment as a legitimate mechanism to enable them to control their own destiny and decisions (Markus \& Schwartz, 2010). Therefore, we expect the effects of customer empowerment on non-adherence to be less detrimental, or more beneficial, in highmastery cultures, as compared to the high-harmony cultures.

\section{Data and Method}

\subsection{Institutional Context}

Healthcare decisions provide a highly relevant context in which to study customer adherence to expert advice (Schwartz, Luce \& Ariely, 2011; Stremersch, 2008). In this domain, expert advice may be a therapy plan prescribed or recommended by the physician to a consumer, or patient. As stated in the introduction, therapy non-adherence generates enormous costs for society and lost sales for pharmaceutical firms, triggering significant attention in the marketing literature (Stremersch \& Van Dyck, 2009; Wosinska, 2005).

Dellande, Gilly and Graham (2004) show that consumer-nurse homophily is an important antecedent of therapy adherence in weight-clinics. Kahn and Luce (2003) find that false-positive results reduce planned adherence among women in mammography waiting rooms. Bowman, Heilman and Seetharaman (2004) find that therapy non-adherence decreases around a doctor 
visit. Wosinska (2005) shows that direct-to-consumer advertising (DTCA) modestly decreases consumer non-adherence using a 4-year panel of prescription claims. Neslin, Rhoads and Wolfson (2009) introduce a method to identify consumers with high risk of non-adherence.

We also control for other domain-specific drivers of unintentional and reasoned nonadherence to therapy advice, inspired by prior literature and befitting our theory above. In particular, we control for sociodemographics (DiMatteo, 2004), consumer-physician homophily (Dellande, Gilly \& Graham, 2004), relationship quality (Palmatier et al., 2006), duration, frequency of interaction and time since last encounter (Doney \& Cannon, 1997), consumer's perceived doctor expertise (given the role of expert power in our theory), consumer health status (DiMatteo, 2004), health motivation (Moorman \& Matulich, 1993), and consumer medical knowledge (World Health Organization, 2003). Figure 2 summarizes our conceptual framework.

--- Insert Figure 2 About Here ---

\subsection{Data Collection Method}

We surveyed 11,735 consumers in Belgium, Brazil, Canada, Denmark, Estonia, France, Germany, India, Italy, Japan, the Netherlands, Poland, Portugal, Singapore, Switzerland, the UK and the US. Medical scholars have established the effectiveness of self-reports of consumers on therapy adherence (Gehi et al., 2007), which correlates highly with biological measures like plasma viraemia (Walsh, Mandalia \& Gazzard, 2002). Reverse causality and common method variance are two well-known concerns with cross-sectional survey research (Rindfleisch et al., 2008). Section 6 provides process evidence to establish directionality. Regarding common method variance, we conducted Harmon's one-factor test (Podsakoff et al. 2003), and the single factor hypothesis was rejected in all countries. We also relied on different response scales and anchors (e.g. 'never' to 'very often' for non-adherence, and 'strongly disagree' to 'strongly 
agree' for informational empowerment), which has been shown to be an effective strategy to reduce common method bias (Rindfleisch et al., 2008). Our estimated effects also show opposite signs (e.g. decisional empowerment versus relationship quality), which is also incompatible with similar response behavior across items.

To the best of our knowledge, this is the largest study of the relationship between consumer empowerment and therapy non-adherence to date. We contracted SSI (Survey Sampling International) to execute our survey on their online panels. Recruiting and rewarding procedures for SSI panels are constantly evaluated in terms of sample representativeness and respondent's attention and motivation.

We selected this sample of countries, because: (1) it contains sufficient cross-cultural variation; (2) consumers are free to choose their physician and typically develop repeated interactions with the same physician in each sampled country; (3) survey costs per country were not greater than $\$ 10,000$. We excluded respondents that were younger than 25 or that had less than three visits with their current general practitioner, in order to guarantee respondent ability to assess the interaction with her physician and therapy non-adherence.

We constructed the original survey in English, which native speakers translated to Danish, Dutch, English, Estonian, French, German, Italian, Japanese, Polish and Portuguese. Another native speaker (the back-translator) translated the survey from his native tongue back to English. The translators and back-translators were doctoral students in social sciences, fluent in English, attending a large European and a large American university. We discussed the translated surveys with both translators and back-translators, iteratively, until we were sure that the final survey retained exactly the same meaning in all languages. The vast majority of these graduate 
students were familiar with survey research methods, often through their coursework, which allowed us to discuss survey items, and their meanings, in detail.

\subsection{Measurement: Individual-Level Constructs}

In Tables A1-A4 (see Appendix) we provide our measures, their respective sources, their reliabilities, and descriptive statistics for each focal construct and for each country. To ensure the validity of our measures, we discussed, ex ante, all items in the survey with researchers in marketing and two doctoral students in medicine to guarantee that the items were understandable and showed content validity. We typically asked the colleague to define the construct in his own words before showing her or him our proposed items and then ask for their agreement with the proposed operationalization. We pretested our purified measures in Singapore (186 subjects), The Netherlands (114 subjects) and the US (102 subjects). The pattern of answers in this pretest increased our confidence on the validity of our measures. We discarded these data and rolled-out the final survey simultaneously in all countries.

In the full sample, all scales had a reliability of at least .7, with the two-item measure for consumer health motivation as only exception $(\rho=.60)$. We used, five-point, multi-item scales for all constructs with the following exceptions. We used a single-item for decisional empowerment, because the measurement object (treatment choice) and its associated attribute (who is in charge of treatment choice) can both be easily envisioned by respondents (Bergkvist \& Rossiter, 2007). This is also consistent with Usta and Häubl's (2011) measurement of 'involvement of self in decision' construct. We also used single items for health status (see Safran et al., 1998), age, education, gender, income, socioeconomic status, gender homophily, age homophily, 
relationship duration, interaction frequency and time since last visit. Unless indicated otherwise (see Appendix), we used demeaned scores for these exogenous observed constructs.

\subsection{Measurement: Country-Level National Culture}

We obtained country-specific scores of national culture for all 17 countries from Shalom Schwartz, which are based on equally weighting scores of college students of varied majors and of schoolteachers of varied topics. These scores are similar to Schwartz (1994), but differ somewhat from these original teacher and student scores, because of the addition of new samples and updated measures (see Schwartz, 2009 for more details).

Schwartz's (1994) cultural values theory relies on the concept of "societal means" for different cultural values, which are obtained by aggregating individual value priorities. These "societal means" capture the latent cultural orientations to which all individuals are exposed and, especially in social contexts (like customer-expert interactions), to which they tend to adapt (Fischer \& Schwartz, 2011). Yet, Schwartz's conceptualization of culture as external to the individual allows for substantial variation of individual values around these "societal means" and avoids the assumption of high within-society value consensus (Schwartz, 2011).

These cultural dimensions are therefore appropriate for cross-country comparisons but not for characterizing the values of individuals, which fits our research purposes. In crosscultural analyses, it is important to avoid the problem of ecological fallacy. Ecological fallacy occurs when researchers assume that nation-level variables directly apply to individuals (Bond, 2002). In our case, the usage of national-level cultural dimensions is appropriate because we are interested in the role of culture as a moderator of the country-level effects of customer empowerment on non-adherence. 


\subsection{Model Specification}

In our models, $i$ indexes respondents $(i=1, \ldots, \mathrm{N} ; \mathrm{N}=11,735), c$ indexes countries $(c=1, \ldots, C$; $C=17), p$ indexes response items measuring latent constructs $(p=1, \ldots, P ; P=28), q$ indexes latent endogenous constructs $(q=1, . ., Q ; Q=2)$, and $r$ indexes latent exogenous constructs $(r=1, \ldots, R$; $R=6$ ). We specify our measurement equations relating the latent endogenous constructs unintentional non-adherence (UNA) and reasoned non-adherence (RNA) - to the observed responses as follows:

$$
\begin{aligned}
& y_{i p}^{c}=\tau_{i p}^{c}+\lambda_{p}^{c} \cdot U N A_{i}+\varepsilon_{i p}^{c}, \text { for } 1 \leq p \leq 4 . \\
& y_{i p}^{c}=\tau_{i p}^{c}+\lambda_{p}^{c} \cdot R N A_{i}+\varepsilon_{i p}^{c}, \text { for } 5 \leq p \leq 9 .
\end{aligned}
$$

And for the latent exogenous constructs as follows:

$$
y_{i p}^{c}=\tau_{i p}^{c}+\lambda_{p}^{c} \cdot \xi_{i r}+\varepsilon_{i p}^{c}, \text { for } p>9 .
$$

Where $\xi_{i r}$ denotes an exogenous latent variable (i.e. expert facilitation of informational empowerment (EFIE), consumer-initiated informational empowerment (CIIE), relationship quality, consumer medical knowledge, health motivation and perceived doctor expertise). $\tau_{i p}^{c}$ are individual-specific random intercepts that account for systematic differences in scale usage across individuals and countries. We extend a model by Maydeu-Olivares and Coffman (2006), and partition the individual-specific random intercepts into a fixed component $\mu_{p}^{c}$, common to all respondents in country $c$ but specific for item $p$, and a scale usage heterogeneity component, $\varsigma_{i}^{c}$, which varies from respondent to respondent but is common to all items:

$$
\tau_{i p}^{c}=\mu_{p}^{c}+\varsigma_{i}^{c}, \text { for all } p
$$


The mean and variance of the scale usage heterogeneity component in Equation $4\left(\varsigma_{i}^{c}\right)$ are country-specific ( $\bar{\varsigma}^{c}$ and $\left.\sigma_{c, \zeta}^{2}, c=1, \ldots, 17\right)$. Note that $\tau_{i p}^{c}$, in Equation 4, captures each respondent's baseline tendency to score high (or low) in each of the constructs we measure. For instance, baseline tendencies for non-adherence are captured by $\tau_{i p}^{c}$, where $1 \leq p \leq 9$. For model identification, we assume that the $\varsigma_{i}^{c}$ 's are uncorrelated with the error terms and with the latent factors, which implies that differences in the usage of response scales are not related to respondents' scores in the constructs being measured (see Maydeu-Olivares \& Coffman, 2006).

We collect the error terms in Equations 1-3 in a single $(P \times 1)$ random vector of residuals, $\boldsymbol{\varepsilon}_{\mathrm{i}}^{\mathbf{c}}$, which we assume to be normally distributed as $\mathrm{N}\left(\mathbf{0}, \Psi^{\mathbf{c}}\right)$, where $\Psi^{\mathrm{c}}$ is a $(P \times P)$ diagonal covariance matrix. The error terms are orthogonal to the latent factors.

Our structural model is defined as:

$$
\begin{aligned}
& U N A_{i}=\beta_{E F I E>U N A}^{c} \cdot E F I E_{i}+\beta_{C I I E>U N A}^{c} \cdot C I I E_{i}+\beta_{D E>U N A}^{c} \cdot D E_{i}+\Gamma_{1}^{\prime}\left[\begin{array}{l}
\xi_{i}^{*}{ }^{*} \\
\mathbf{X}_{\mathbf{i}}
\end{array}\right]+\delta_{1, i}^{c} \\
& R N A_{i}=\beta_{E F I E>R N A}^{c} \cdot E^{c}+\beta_{C I I E>R N A}^{c} \cdot C I I E_{i}+\beta_{D E>R N A}^{c} \cdot D E_{i}+\Gamma_{2}^{\prime}\left[\begin{array}{l}
\xi_{i}^{*}{ }_{i}^{*} \\
\mathbf{X}_{\mathbf{i}}
\end{array}\right]+\delta_{2, i}^{c}
\end{aligned}
$$

Where the $\beta^{c}$ parameters ${ }^{5}$ are country-specific parameters capturing the effects of customer empowerment on unintentional and reasoned non-adherence. $\xi_{i}^{*, c}$ is a vector where we collect all exogenous latent variables besides the customer empowerment constructs (i.e. relationship quality, consumer medical knowledge, health motivation and perceived doctor expertise), $\mathbf{X}_{\mathbf{i}}$ is a

${ }^{5}$ That is, $\left\{\beta_{E F I E>U N A}^{c}, \beta_{C I I D \backslash N A}^{c}, \beta_{D E>U N A}^{c}, \beta_{E F I E>R N A}^{c}, \beta_{C I I E>R N A}^{c}, \beta_{D E>N N A}^{c}\right\}$, for all $c$. 
vector where we collect all remaining control variables (i.e. all observed independent variables). Consequently, $\boldsymbol{\Gamma}_{\mathbf{q}}$, for $q=1,2$, contain the structural paths corresponding to the control variables, pooled across countries. We collect all exogenous latent variables in a $(R \times 1)$ vector $\xi_{\mathbf{i}}^{\mathbf{c}}=\left[\begin{array}{llll}E F I E_{i} & C_{i} & D E_{i} & \xi_{i}^{*}{ }^{*}\end{array}\right]^{\prime}$ distributed according to $\mathrm{N}\left(\mathbf{0}, \boldsymbol{\Phi}^{\mathbf{c}}\right)$, where $\boldsymbol{\Phi}^{\mathbf{c}}$ is a $(\mathrm{R} \times \mathrm{R})$ full covariance matrix ${ }^{6}$ and we assume the residuals, $\delta_{q, i}^{c}$, are independent of the latent variables and distributed $\mathrm{N}\left(0, \psi_{\delta, q}^{c}\right)$, for $q=1,2$.

\subsection{Estimation}

We use Bayesian estimation, which is a more flexible approach to the estimation of theorydriven structural equation models than maximum likelihood (Muthén \& Asparouhov, 2012). We specify the posterior distribution of the parameters of interest across all respondents and estimate the model simultaneously across all countries. We sample the model parameters from their posterior distributions using the Gibbs sampler (Casella \& George, 1992) with data augmentation, which allows sampling the latent constructs alongside the model parameters (Tanner \& Wong, 1987).

Bayesian estimation also facilitates our task of assessing the moderating effects of culture in our model. In particular, at each iteration of our Gibbs sampler, we store the correlations between each of the country-specific paths in our structural model (i.e. the $\beta^{c}$ parameters) and Schwartz's (1994) culture dimensions. We use standard diffuse priors for our parameters (normal distributions for measurement intercepts, loadings and structural parameters and inverse-Wishart distributions for variance-covariance matrices).

\footnotetext{
${ }^{6}$ A full covariance matrix allows us to control for covariation among exogenous latent constructs (Lee, 2007).
} 


\subsection{Identification and measurement invariance}

In addition to the standard distributional assumptions, discussed above, for the residuals, for the random intercepts ( $\tau_{i p}^{c}$, in line with Maydeu-Olivares \& Coffman, 2006) and for $\boldsymbol{\xi}_{\mathbf{i}}^{\mathbf{c}}($ which identify the item intercepts), we follow the normal practice of setting the factor loading of one item per construct (the marker item) to unity (which identifies the scale of the latent constructs). In addition, for meaningful cross-national comparisons, we need a sufficient degree of metric invariance across countries. Following Steenkamp and Baumgartner (1998), we test the hypothesis of full metric invariance by constraining the matrix of factor loadings to be invariant across countries. The configural model has a smaller DIC $\left(\mathrm{DIC}_{\text {config }}=611,998\right)$ than the metric invariance model $\left(\mathrm{DIC}_{\operatorname{minv}}=613,385\right)$, which means that we do not find support for full metric invariance (DIC: deviance information criterion; see Spiegelhalter et al., 2002).

Full metric invariance is very unlikely (Steenkamp \& Baumgartner, 1998, p.81) and Byrne, Shavelson \& Muthén (1989) have established that partial metric invariance is sufficient for cross-cultural equivalence and meaningful cross-national comparison. In order to understand the lack of full metric invariance, we compared the factor loadings from the measurement invariance model with those of the configural model. We first stored, at each draw, the 20 factor loadings across the 17 countries in our sample obtained from the configural model. Next, we computed the $95 \%$ credible intervals for each of these 340 loadings across the posterior draws from our MCMC chain. We then examined whether the $95 \%$ credible interval for each of the country-specific loadings from the configural model contained the posterior median of the corresponding factor loading estimated using the metric invariance model. This was the case in 243 out of the 340 loadings (i.e. $71.5 \%$ of the loadings; see Table A3 in the Appendix for a cross-country comparison). More importantly, when comparing the structural path estimates 
between the metric invariance and the configural models we saw no meaningful differences. The correlation between the focal structural paths (capturing the effects of customer empowerment on non-adherence) in the configural and metric invariance models is .99 and we do not find any significant difference across paths. In other words, in all cases, the $95 \%$ credible intervals of the structural paths in the metric invariance model contained the posterior mean of the same path according to the configural model and vice versa. Overall, these results provide strong evidence that we have sufficient cross-country equivalence to make cross-national inferences.

\section{Results}

\section{1. $\quad$ Non-Adherence to Expert Advice across Countries}

Figure 3 plots the mean levels of unintentional and reasoned non-adherence across countries in our sample, computed by averaging, across the MCMC draws, the measurement intercepts $\left(\tau_{i p}^{c}\right)$. We do not restrict the measurement intercepts across countries, since the latent means are constrained to be equal, which ensures meaningful cross-national comparison. The dashed lines in Figure 3 represent the median levels. While there is a positive relationship between unintentional and reasoned non-adherence, the relationship is not perfect ( $\rho=.80$ and a linear regression of RNA on UNA has an $\mathrm{R}^{2}$ of .64). Consumers in Estonia, Japan, India and Singapore exhibit considerably higher levels of non-adherence than consumers in Denmark and the Netherlands.

--- Introduce Figure 3 about here ---

\subsection{Customer Empowerment and Non-Adherence to Expert Advice}

Table 1 presents the estimated coefficients from our multi-sample structural equation model with country-specific random effects in the measurement model capturing scale usage heterogeneity. 
We let all chains converge by running our models for 25,000 iterations, discarding the first 10,000 for burn-in, and using the subsequent 1,500 thinned draws (we used every $10^{\text {th }}$ draw to reduce autocorrelation) for posterior inference. The estimates are the posterior cross-country medians obtained from the MCMC chains from our Gibbs-sampler ${ }^{7}$. Bolded figures represent estimates for which the $95 \%$ credible interval (the interval between the $2.5^{\text {th }}$ and the $97.5^{\text {th }}$ percentiles of the distribution of MCMC draws) does not contain zero.

--- Insert Table 1 about here ---

Even though we find a positive relationship between expert facilitation of informational empowerment (EFIE) and non-adherence, the relationship was neither significant ${ }^{8}$ for unintentional non-adherence $\left(\bar{\beta}_{E F E>U N A}=.04 ; 95 \% \mathrm{CI}=[-.01 ; .09]\right)$ nor for reasoned nonadherence $\left(\bar{\beta}_{E F I E>R N A}=.04 ; 95 \% \mathrm{CI}=[-.02 ; .09]\right)$. These initial results do not support $\mathrm{H}_{1}$ and $\mathrm{H}_{2}$. In support of $\mathrm{H}_{3}$, customer-initiated informational empowerment (CIIE) is associated with lower levels of unintentional non-adherence $\left(\bar{\beta}_{\text {CIIE } \backslash U N A}=-.22 ; 95 \% \mathrm{CI}=[-.28 ;-.17]\right)$. CIIE is also associated with lower reasoned non-adherence $\left(\bar{\beta}_{C I E>R N A}=-.16 ; 95 \% \mathrm{CI}=[-.21 ;-.11]\right)$, which suggests that the motivational benefits of discussing, during an advising interaction, solution-relevant information that customers finds self-relevant are stronger than the detrimental effects of such discussion on customer overconfidence.

\footnotetext{
${ }^{7} \mathrm{We}$ obtain these posterior cross-country medians by averaging, at each draw, the beta parameters -

$\left\{\beta_{E F I E>U N A}^{c}, \beta_{C I I>U N A}^{c}, \beta_{D E>U N A}^{c}, \beta_{E F I E>R N A}^{c}, \beta_{C I I E>R N A}^{c}, \beta_{D E>R N A}^{c}\right\}$, for all $c$ - across countries and then obtaining the posterior median of these averages.

${ }^{8}$ We use the term "significant" whenever the $95 \%$ credible interval of a certain parameter does not contain zero.
} 
In support of hypotheses $\mathrm{H}_{4}$ and $\mathrm{H}_{5}$, decisional empowerment (DE) is associated with higher unintentional non-adherence $\left(\bar{\beta}_{D E>U N A}=.04 ; 95 \% \mathrm{CI}=[.03 ; .06]\right)$ and with higher reasoned non-adherence $\left(\bar{\beta}_{D E>R N A}=.08 ; 95 \% \mathrm{CI}=[.06 ; .10]\right)$.

\section{3. $\quad$ Other Drivers of Non-Adherence to Expert Advice}

Table 2 presents the estimates for the control variables. Our results are in line with the findings of prior literature. We discuss several interesting paths, while a more detailed note on all effects is available from the first author upon request. The results on sociodemographics are consistent with the medical literature (DiMatteo, 2004) and recent research in marketing (Neslin, Rhoads \& Wolfson 2009), which find no or modest effects of sociodemographics on non-adherence.

--- Insert Table 2 about here ---

The beneficial effects of relationship quality on therapy non-adherence are consistent with the relationship marketing literature (Geyskens, Steenkamp and Kumar 1998; Morgan \& Hunt, 1994). Gender homophily is associated with lower levels of unintentional non-adherence, but not reasoned non-adherence. The latter effect is consistent with prior research in marketing (Dellande, Gilly \& Graham, 2004). Reasoned non-adherence decreases with interaction frequency, which is not true for unintentional non-adherence. Reasoned non-adherence also tends to increase between visits, in line with Bowman, Heilman \& Seetharaman (2004). We do not find such an effect for unintentional non-adherence.

\section{Process Evidence}

We now discuss process evidence on the effects of customer empowerment on unintentional and reasoned non-adherence. We use customer-centered communication quality (i.e., the extent to which the customer believes that her doctor spends sufficient time, during an advising interaction, sharing clear and understandable information with her, see Kao et al., 1998) and 
locus of control (the customer's confidence in her own ability to cure herself, see Moorman and Matulich, 1993) as mediators (see Table 3). We first discuss the influence of these mediators on non-adherence, after which we turn to the influence of empowerment on these mediators.

In line with our expectations, high customer-centered communication quality is

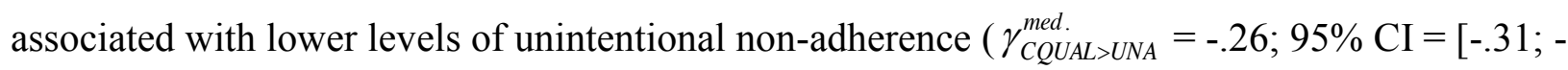
$.22])$ and reasoned non-adherence $\left(\gamma_{C Q U A L>R N A}^{\text {med. }}=-.29 ; 95 \% \mathrm{CI}=[-.34 ;-.25]\right)$. Also as theorized, high locus of control - i.e. our proxy for customer overconfidence - is associated with higher levels of unintentional $\left(\gamma_{\text {LOCUS }>U N A}^{\text {med. }}=.03 ; 95 \% \mathrm{CI}=[.02 ; .05]\right)$ and reasoned non-adherence ( $\left.\gamma_{\text {LOCUS }>R N A}^{\text {med. }}=.09 ; 95 \% \mathrm{CI}=[.07 ; .11]\right)$.

--- Insert Table 3 about here ---

Expert facilitation of informational empowerment (EFIE) is associated with higher

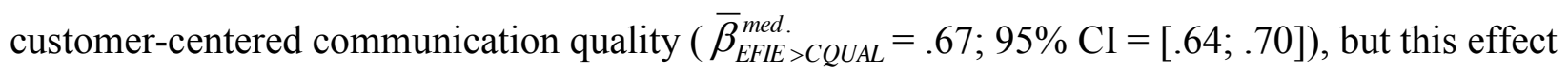
is offset by a direct effect on unintentional non-adherence $\left(\bar{\beta}_{E F I E>U N A}^{\text {med. }}=.25 ; 95 \% \mathrm{CI}=[.18 ; .31]\right)$. This is consistent with the logic under $\mathrm{H}_{1}$. That is, unrequested solution-relevant information makes the advice harder to recall and may crowd out other pieces of information that may be more relevant to stimulate adherence (Epstein, Korones, \& Quill, 2010), offsetting the beneficial impact of EFIE on customer-centered communication quality. EFIE is negatively, but

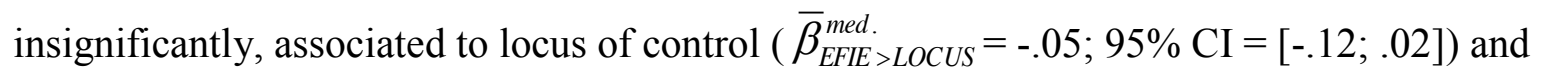

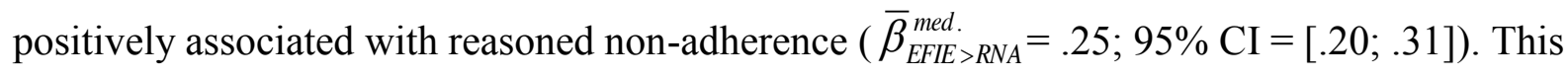
suggests that EFIE increases customers' tendency to egocentrically discount the expert's advice, in line with the behavioral mechanism underlying $\mathrm{H}_{2}$. 
Customer-initiated informational empowerment (CIIE) is associated with worse

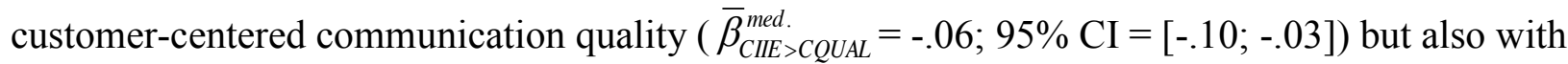
lower unintentional non-adherence $\left(\bar{\beta}_{C I I E>U N A}^{\text {med. }}=-.23 ; 95 \% \mathrm{CI}=[-.29 ;-.18]\right)$. These two effects are consistent with the relations we theorized in $\mathrm{H} 3$. That is, even though when compared to a paternalistic model, CIIE may decrease communication quality - for instance, because it increases time pressure during an advising interaction (Dugdale, Epstein, \& Pantilat, 1999) - it increases customer motivation, facilitating understanding and future recall of the expert advice. CIIE is associated with higher locus of control $\left(\bar{\beta}_{\text {CIIE }>\text { LOCUS }}^{\text {med }}=.24 ; 95 \% \mathrm{CI}=[.15 ; .31]\right)$ and with lower reasoned non-adherence $\left(\bar{\beta}_{C I I E>R N A}^{\text {med. }}=-.16 ; 95 \% \mathrm{CI}=[-.22 ;-.11]\right)$. These results suggest that while CIIE may also trigger overconfidence to a certain extent, the fact that it affords an opportunity for experts to explain and clarify their advice leads to lower reasoned non-adherence. Similarly, decisional empowerment (DE) is associated with worse customer-centered communication quality $\left(\bar{\beta}_{D E>C Q U A L}^{\text {med. }}=-.03 ; 95 \% \mathrm{CI}=[-.04 ;-.02]\right)$, with higher locus of control ( $\left.\bar{\beta}_{D E>L O C U S}^{\text {med. }}=.11 ; 95 \% \mathrm{CI}=[.04 ; .16]\right)$, and both with higher unintentional non-adherence ( $\left.\bar{\beta}_{D E>U N A}^{\text {med. }}=.04 ; 95 \% \mathrm{CI}=[.02 ; .05]\right)$ and reasoned non-adherence $\left(\bar{\beta}_{D E>R N A}^{\text {med. }}=.07 ; 95 \% \mathrm{CI}=[.05\right.$; .08]). These effects are also consistent with the relations we theorized in $\mathrm{H}_{4}$ and $\mathrm{H}_{5}$. In sum, the empirical relations we uncover through our mediation analyses are logically consistent with our theoretical expectations.

\section{National-Cultural Effects}

We now analyze cross-country differences in the relationship between customer empowerment and adherence to expert advice. The posterior cross-country standard deviations, in the last 
column of Table 1, are all relatively high when compared with the corresponding posterior medians $\left(\sigma_{E F I E>U N A}=.13 ; \sigma_{E F I E>R N A}=.13 ; \sigma_{C I I E>U N A}=.15 ; \sigma_{C I I E>R N A}=.17 ; \sigma_{D E>U N A}=.05 ; \sigma_{D E>R N A}=.05\right)$. Table 4 presents the posterior correlations between the country-specific posterior estimates for the paths between customer empowerment and non-adherence and Schwartz's country-specific cultural dimensions. This analysis revealed that the effects of decisional empowerment and, to a lesser extent, of customer-initiated informational empowerment and expert facilitation of informational empowerment on non-adherence are moderated by culture. Culture is a stronger moderator of RNA (ten posterior correlations with $95 \%$ credible intervals not containing zero) than of UNA (two posterior correlations with $95 \%$ credible intervals not containing zero). We first discuss the moderating effects of culture on the relationship between decisional empowerment and non-adherence.

--- Insert Table 4 about here ---

In high-embeddedness cultures $\left(\rho_{[D E>R N A], E M B E D D E D N E S S}=-.31,95 \% \mathrm{CI}=[-.57 ;-.00]\right)$, high-hierarchy cultures $\left(\rho_{[D E>R N A], H I E R A R C H Y}=-.34,95 \% \mathrm{CI}=[-.60 ;-.01]\right)$, and high-mastery cultures $\left(\rho_{[D E>R N A], M A S T E R Y}=-.40,95 \% \mathrm{CI}=[-.67 ;-.06]\right)$, decisional empowerment is less detrimental as it increases reasoned non-adherence less than in other cultures. In high-intellectual autonomy cultures $\left(\rho_{[D E>R N A], I N T E L L . A U T O N O M Y}=.44,95 \% \mathrm{CI}=[.15 ; .69]\right)$ and harmonious cultures $\left(\rho_{[D E>R N A], H A R M O N Y}=.57,95 \% \mathrm{CI}=[.32 ; .77]\right)$, decisional empowerment increases reasoned nonadherence more than in other cultures. We also find that in harmonious cultures, decisional empowerment increases unintentional non-adherence more than in other cultures $\left(\rho_{[D E>U N A], H A R M O N Y}=.36,95 \% \mathrm{CI}=[.05 ; .62]\right)$. These effects are in line with our theory-driven expectations. For instance, when compared with customers in high-mastery societies, customers in harmonious societies should perceive decisional empowerment as more incongruent with the 
expected roles of customers and experts. Higher perceived incongruence, in turn, should magnify the detrimental effects of decisional empowerment on unintentional and reasoned non-adherence. The effect of expert facilitation of informational empowerment (EFIE) on reasoned nonadherence is less detrimental in high-hierarchy countries $\left(\rho_{[E F I E>R N A], H I E R A R C H Y}=-.56,95 \% \mathrm{CI}=[-\right.$ $.79 ;-.16])$ but more detrimental in high-egalitarianism cultures $\left(\rho_{[\text {EFIE }>R N A], \text { EGALITARIANISM }}=.40\right.$, $95 \% \mathrm{CI}=[.02 ; .65])$. The effect of EFIE on unintentional non-adherence is also less detrimental in high-hierarchy countries $\left(\rho_{[\text {EFIE }>U N A], H I E R A R C H Y}=-.45,95 \% \mathrm{CI}=[-.71 ;-.08]\right)$, as compared to customers in less hierarchical countries. In high-hierarchy cultures, customers are less likely to engage in behaviors that threaten the expert's role and, thus, EFIE has less detrimental effects than in other countries (e.g. high-egalitarianism).

Finally, the beneficial effect of customer-initiated informational empowerment (CIIE) on reasoned non-adherence is weaker in high-affective autonomy and high-intellectual autonomy cultures than in other cultures $\left(\rho_{[\text {CIIE }>R N A], A F F . A U T O N O M Y}=.40,95 \% \mathrm{CI}=[.13 ; .64]\right.$;

$\left.\rho_{\text {[CIIE }>\text { RNA] }, I N T . A U T O N O M Y}=.35,95 \% \mathrm{CI}=[.03 ; .59]\right)$ but stronger in high-embeddedness cultures $\left(\rho_{[C I I E>R N A], E M B E D D E D N E S S}=-.43,95 \% \mathrm{CI}=[-.66 ;-.11]\right)$. Compared with customers in highembeddedness cultures, customers in more autonomous cultures may have a tendency to be vocal (high CIIE) but also to follow their own opinion even if that entails discounting an expert's opinion (high RNA).

\section{Conclusion}

We study the effect of customer empowerment on the adherence to expert advice in the context of medical treatment decisions. We organize different customer-expert decision-making styles according to the distinction between expert facilitation of informational empowerment, customer-initiated informational empowerment and decisional empowerment. In line with the 
beneficial effects attributed to customer empowerment in the prior literature, we find that customer-initiated informational empowerment reduces both unintentional and reasoned nonadherence. However, contrary to these beneficial attributions, we uncover that decisional empowerment increases unintentional and reasoned non-adherence. In addition, expert facilitation of informational empowerment improves the quality of customer-centered communication but may increase the cognitive and emotional burden for the customer and crowd out important pieces of information. These detrimental effects offset the benefits of expert facilitation of informational empowerment on customer-centered communication quality.

We find that culture moderates several of these relationships. For instance, in countries where decisional empowerment is congruent with national culture, its detrimental effects can be somewhat reduced. For example, in high-mastery cultures, such as the U.S., decisional empowerment triggers less customer overconfidence and thus less reasoned non-adherence. Exploring such cross-cultural heterogeneity allowed us to better understand in which cultures empowerment may have the largest or smallest impact on non-adherence.

\subsection{Implications}

These findings provide important and counterintuitive insights. The current thinking among many scholars is that shared informed autonomy (high decisional and informational empowerment) is the customer-expert decision-making model that minimizes non-adherence to expert advice (Epstein, Alper \& Quill, 2004; Macfarlane, 2008). Financial and tax advisors, lawyers, doctors and management consultants - to name just a few - routinely consider whether accommodating the whims and opinions of their customers (versus maintaining a strong opinion and decision control) would help them achieve better results (Usta \& Häubl, 2011), in particular higher customer adherence to their advice (Epstein, Alper \& Quill 2004; Quill \& Brody, 1996). 
In contrast with this view, we find that customer-driven informed delegation is the model that minimizes non-adherence to expert advice. The underpinnings of this model are that: (1) decision power should remain with the expert if the expert wishes the customer to adhere to her advice, (2) customers should be allowed to ask questions and offer their opinion, and (3) experts should not proactively facilitate informational empowerment.

In the specific case of patient-doctor interactions - the institutional context of our empirical analysis - these findings are particularly timely. From the famous paternalistic scenes in the movie "Patch Adams," the medical decision-making model is now undergoing increasing pressure to be more consumer-centric. In light of our findings, the concern that consumercentricity may in practice turn to healthcare consumerism and reduce healthcare quality (Camacho, 2014; Starkey, 2003), seems valid for treatment non-adherence. In the optimal model - customer-driven informed delegation - the physician acts as an agent to whom customers delegate authority (a feature also present in the paternalistic model) and is responsive, but not proactive, to exchange solution-relevant information (a feature that is not present in the paternalistic model).

Cross-national heterogeneity in the magnitude of our effects allows us to offer some culturally-specific implications. In particular, sharing more decision power with customers would be less detrimental for experts in the US (a culture that emphasizes mastery and selfassertion) than for experts in many Western European countries such as Denmark, France, Germany, and the Netherlands (cultures that emphasize harmony and intellectual autonomy).

\section{2. $\quad$ Future Research}

Our study has several limitations that can open new avenues for future research. First, future research using revealed customer adherence data, for instance, from script refills, holds great 
promise, because it shows greater external validity. On the other hand, such data may contain less detail (e.g. no distinction between reasoned and unintentional non-adherence), possibly contain self-selection mechanisms (e.g. most patient-monitoring programs are opt-in) and be hard to obtain.

Second, in this paper, we study customer non-adherence as a behavioral trait (in line for instance with DiMatteo et al., 1993 and Bowman, Heilman \& Seetharaman, 2004). Despite this tradition, it would be interesting if future research would look into context-specific motivations for adherence. Most studies have also focused on patient adherence to physician advice. It would be interesting if future work in marketing explored customer non-adherence in contexts beyond healthcare, such as consulting, financial or tax advice, legal advice, etc.

Third, in our cultural analyses, we rely on country-level cultural scores and test whether these scores predict variation in country-specific effects of customer empowerment on adherence to expert advice. Future research could rely on individual-level value scores to explore withincountry value heterogeneity and test the sensitivity of our results to the unit of analysis chosen for cultural inferences.

Fourth, future research could also explore behavioral interventions aimed at reducing unintentional and/or reasoned non-adherence to treatment advice. For instance, Adhere.IO is a behavioral diagnostic invented at MIT that uses lateral flow technology - the technology used in pregnancy tests - to verify, remotely, if a patient took her drugs on time and reward those who accurately follow the therapy advice (Gomez-Marquez, 2013). Future studies could help optimize this type of behavioral interventions to maximize reduction of unintentional and/or reasoned non-adherence. 
Fifth, in this study we assumed that the customer seeks the advice of a single expert. Research on advice-taking, however, suggests that integrating the advice of multiple experts may improve customers' decisions (Bonaccio \& Dalal, 2006; Budescu et al., 2003). Future research could thus examine how customers integrate and weigh the advice from multiple experts possibly with distinct decision-making styles.

Sixth, there are also many situations where adherence to expert advice is not an individual, but a group decision. For instance, when lawyers or management consultants advise an executive committee on a litigation or business strategy, adherence to the expert's advice is determined through negotiation among the members of the executive committee. Future research may explore advice-giving to multiple agents in the same decision-making unit and the optimality of different customer-expert decision-making models in such contexts.

Seventh, existing research on dual-process models has identified several antecedents of people's tendency to engage in heuristic or systematic information processing (e.g. Chaiken, Liberman, \& Eagly, 1989). Future research could further explore customer, expert and customerexpert interaction characteristics that may trigger the activation of these different types of information processing modes and influence customer adherence to expert advice.

In general, the present paper may inform policy discussions on patient empowerment. It may also guide experts on how to engage with their customers, to the extent they want their customers to adhere to their advice. Finally, it also may be informative for customers, because they may themselves suffer from not adhering to expert advice. 


\section{References}

Abele, A.E., \& Gendolla, G.H.E. (2007). Individual differences in optimism predict the recall of personally relevant information. Personality and Individual Differences, 43, 1125-1135.

Bergkvist, L. \& Rossiter, J.R. (2007). The predictive validity of multiple-item versus single-item measures of the same constructs. Journal of Marketing Research, 44 (2), 175-184.

Bohner, G., Moskowitz, G. B., \& Chaiken, S. (1995). The interplay of heuristic and systematic processing of social information. European Review of Social Psychology, 6, 33-68.

Bonaccio, S. \& Dalal, R.S. (2006). Advice taking and decision-making: An integrative literature review, and implications for the organizational sciences. Organizational Behavior and Human Decision Processes, 101, 127-151.

Bond, M.H. (2002). Reclaiming the individual from Hofstede's ecological analysis - A 20-year odyssey: Comment on Oyserman et al. (2002). Psychological Bulletin 128(1): 73-77.

Bond, M.H. et al. (2004). Culture-level dimensions of social axioms and their correlates across 41 countries. Journal of Cross-Cultural Psychology, 35(5), 548-570.

Botti, S., \& McGill, A.L. (2011). The locus of choice: Personal causality and satisfaction with hedonic and utilitarian choices. Journal of Consumer Research, 37 (April), 1065-1078.

Botti, S., Orfali, K. \& Iyengar, S.S. (2009). Tragic choices: Autonomy and emotional responses to medical decisions. Journal of Consumer Research, 36 (October), 337-352.

Bove, L.L., \& Johnson, L.W. (2006). Customer loyalty to one service worker: Should it be discouraged? International Journal of Research in Marketing, 23, 79-91.

Bowman, D., Heilman, C.M., \& Seetharaman, P.B. (2004). Determinants of product-use compliance behavior. Journal of Marketing Research, 41 (August), 324-338.

Brehmer, B. \& Hagafors, R. (1986). Use of experts in complex decision-making: A paradigm for the study of staff work. Organizational Behavior and Human Decision Processes, 38, 191195.

Brug, J., Steenhaus, I., Van Assema, P., \& de Vries, H. (1996). The impact of computer-tailored nutrition intervention. Preventive Medicine, 25, 236-242.

Budescu, D.V., Rantilla, A.K., Yu, H., \& Karelitz, T.K. (2003). The effects of asymmetry among advisors on the aggregation of their opinions. Organizational Behavior and Human Decisions Processes, 90, 178-194.

Burgess, S.M. \& Steenkamp, J. (2006). Marketing renaissance: How research in emerging markets advances marketing science and practice. International Journal of Research in Marketing, 23, 337-356.

Byrne, B.M., Shavelson, R.J., \& Muthén, B. (1989). Testing for the equivalence of factor covariance and mean structures: The issue of partial measurement invariance. Psychological Bulletin, 105(3), 456-466.

Camacho N. (2014). Patient empowerment: Consequences for pharmaceutical marketing and for the patient-physician relationship. In M. Ding, J. Eliashberg, \& S. Stremersch (Eds.), Innovation and Marketing in the Pharmaceutical Industry: Emerging Practices, Research, and Policies (pp. 425-455). New York: Springer.

Camacho N., Donkers, B., \& Stremersch, S. (2011). Predictably non-Bayesian: Quantifying salience effects in physician learning about drug quality. Marketing Science, 30(2), 305-320. 
Camacho N., Landsman, V., \& Stremersch, S. (2010). The connected patient. In S. Wuyts, M.G. Dekimpe, E. Gijsbrechts, \& R. Pieters (Eds.), The Connected Customer: The Changing Nature of Consumer and Business Markets (pp. 107-139). London: Routledge Academic.

Casella, G. \& George, E.I. (1992). Explaining the Gibbs sampler. The American Statistician, 46 (3), 167-174.

Chaiken, S. (1980). Heuristic versus systematic information processing and the use of source versus message cues in persuasion. Journal of Personality and Social Psychology, 39 (November), 752-766.

Chaiken, S., Liberman, A., \& Eagly, A.H. (1989). Heuristic and systematic information processing within and beyond the persuasion context. In J. S. Uleman, \& J. A. Bargh (Eds.), Unintended thought (pp. 212-252). New York: Guilford.

Charles, C., Gafni, A., \& Whelan, T. (1999). Decision-making in the physician-patient encounter: Revisiting the shared treatment decision-making model. Social Science and Medicine, 49, 651-661.

Charles, C., Gafni, A., \& Whelan, T., \& O’Brien, M.A. (2006). Cultural influences on the physician-patient encounter: The case of shared treatment decision-making. Patient Education and Counseling, 63, 262-267.

Coulter, A. (1999). Paternalism or partnership? British Medical Journal, 319, 719-720.

Dellande, S., Gilly, M.C. \& Graham, J.L. (2004). Gaining compliance and losing weight: The role of the service provider in health care services. Journal of Marketing, 68 (July), 78-91.

DiMatteo, M.R., Sherbourne, C.D., Hays, R.D., Ordway, L., Kravitz, R.L., McGlynn, E.A., Kaplan, S., \& Rogers, W.H. (1993). Physicians' characteristics influence patients' adherence to medical treatment: Results from the medical outcomes study. Health Psychology, 12 (2), 93-102.

DiMatteo, M.R. (2004). Variations in patients' adherence to medical recommendations - A quantitative review of 50 years of research. Medical Care, 42 (3), 200-209.

Doney, P.M., \& Cannon, J.P. (1997). An examination of the nature of trust in buyer-seller relationships. Journal of Marketing, 61(April) 35-51.

Dugdale, D.C., Epstein, R.M., \& Pantilat, S.Z. (1999). Time and the patient-physician relationship. Journal of General Internal Medicine, 14(1), S34-S40.

Epstein, R.M., Alper, B.S., \& Quill, T.E. (2004). Communicating evidence for participatory decision-making. Journal of the American Medical Association, 291 (19), 2359-2366.

Epstein, R.M., Korones, D.N., \& Quill, T.E. (2010). Withholding information from patients When less is more. New England Journal of Medicine, 362(5), 380-381.

Fitzsimons, G., \& Lehmann, D.R. (2004). Reactance to recommendations: When unsolicited advice yields contrary responses. Marketing Science, 23 (1), 82-94.

Fischer, R., \& Schwartz, S. (2011). Whence differences in value priorities? Individual, cultural, or artifactual sources. Journal of Cross-Cultural Psychology, 42(7), 1127-1144.

Forissier, T., \& Firlik, K. (2012). Estimated annual pharmaceutical revenue loss due to medication non-adherence. Capgemini Consulting \& HealthPrize Technologies. Available in http://www.adherence564.com/, accessed November 12, 2013.

Fuchs, C., Prandelli, E., \& Schreier, M. (2010). The psychological effects of empowerment strategies on consumers' product demand. Journal of Marketing, 74 (January), 65-79. 
Gehi, A.K., Ali, S., Na, S., \& Whooley, M.A. (2007). Self-reported medication adherence and cardiovascular events in patients with stable coronary heart disease. Archives of Internal Medicine, 167(16), 1798-1803.

Geyskens, I., Steenkamp, J.B.E.M., \& Kumar, N. (1998). Generalizations about trust in marketing channel relationships using meta-analysis. International Journal of Research in Marketing, 15, 223-248.

Gomez-Marquez, J. (2013). Adhere.IO. In J. Donner, \& P. Mechael (Eds.), mHealth in Practice. New York: Bloomsbury Academic.

Hofstede, G. (2001). Culture's Consequences: Comparing Values, Behaviors, Institutions, and Organizations across Nations ( $2^{\text {nd }}$ Edition). Beverly Hills, CA: Sage.

Inglehart, R., \& Baker, W.E. (2000). Modernization, cultural change and the persistence of traditional values. American Sociological Review, 65, 19-51.

Izraeli, D.M., \& Jick, T.D. (1986). The art of saying no: Linking power to culture. Organization Studies, 7(2), 171-192.

Kahn, B., \& Luce, M.F. (2003). Understanding high-stakes consumer decisions: Mammography adherence following false-alarm test results. Marketing Science, 22 (3), 393-410.

Kao, A., Green, D.C., Zaslavsky, A.M., Koplan, J.P., \& Cleary, P.D. (1998). The relationship between method of physician payment and patient trust. Journal of the American Medical Association, 280 (19), 1708-1714.

Kreuter, M.W., Clark, E.M., Oswald, D.L., \& Bull, F.C. (1999). Understanding how people process health information: A comparison of tailored and nontailored weight-loss materials. Health Psychology, 18(5), 487-494.

Lee, S. (2007). Structural equation modeling: A Bayesian approach. Chichester, West Sussex: John Wiley \& Sons Ltd.

Lerman, C.E., Brody, D.S., Caputo, G.C., Smith, D.G., Lazaro, C.G., \& Wolfson, H.G. (1990). Patients' perceived involvement in care scale: Relationship to attitudes about illness and medical care. Journal of General Internal Medicine, 5, 29-33.

Loh, A., Leonhart, R., Wills, C.E., Simon, D., \& Härter, M. (2007). The impact of patient participation on adherence and clinical outcome in primary care of depression. Patient Education and Counseling, 65, 69-78.

Macfarlane, J. (2008). The new lawyer: How settlement is transforming the practice of law. Vancouver, BC: UBC Press.

Markus, H.R., \& Schwartz, B. (2010). Does choice mean freedom and well-being? Journal of Consumer Research, 37 (August), 344-355.

Maydeu-Olivares, A., \& Coffman, D.L. (2006). Random intercept factor analysis. Psychological Methods, 11(4), 344-362.

Moorman, C., \& Matulich, E. (1993). A model of consumers' preventive health behaviors: The role of health motivation and health ability. Journal of Consumer Research, 20 (2), 208-228.

Morgan, R., \& Hunt, S.D. (1994). The commitment-trust theory of relationship marketing. Journal of Marketing, 58 (3), 20-38.

Morris, L.A., \& Halperin, J.A. (1979). Effects of written drug information on patient knowledge and compliance: A literature review. American Journal of Public Health, 69(1), 47-52.

Muthén, B., \& Asparouhov, T. (2012). Bayesian SEM: A more flexible representation of substantive theory. Psychological Methods, 17(3), 313-335. 
Narayanan, S., \& Manchanda, P. (2009). Heterogeneous learning and the targeting of marketing communication for new products. Marketing Science, 28(3), 424-441.

New England Healthcare Institute (2009). Thinking Outside the Pillbox: A System-wide Approach to Improving Patient Medication Adherence for Chronic Disease. Available in http://www.nehi.net/publications/44/thinking_outside the pillbox_a systemwide_approach to improving patient medication_adherence_for_chronic_disease, accessed November 16 2013.

Neslin, S.A., Rhoads, E.E., \& Wolfson, P. (2009). A model and empirical analysis of patient compliance and persistence in pharmaceuticals. Unpublished Manuscript, Tuck School of Business, Dartmouth College.

Osterberg, L., \& Blaschke, T. (2005). Adherence to medication. New England Journal of Medicine, 353(5), 487-497.

Ozer, E., \& Bandura, A. (1990). Mechanisms governing empowerment effects: A self-efficacy analysis. Journal of Personality and Social Psychology, 58 (3), 472-486.

Palmatier, R.W., Dant, R.P., Grewal, D., \& Evans, K.R. (2006). Factors influencing the effectiveness of relationship marketing: A meta-analysis. Journal of Marketing, 70 (October), 136-153.

Petty, R.E., \& Cacioppo, J.T. (1986), Communication and Persuasion: Central and Peripheral Routes to Persuasion. New York: Springer.

Phelps, C.E. (1992). Health Economics. New York: HarperCollins.

Podsakoff, P.M., MacKenzie, S.B., Lee, J., \& Podsakoff, N.P. (2003). Common method biases in behavioral research: A critical review of the literature and recommended remedies. Journal of Applied Psychology, 88 (5), 879-903.

Quill, T.E., \& Brody, H. (1996). Physician recommendations and patient autonomy: Finding a balance between physician power and patient choice," Annals of Internal Medicine, 125(9), 763-769.

Raaijmakers, J.G., \& Shiffrin, R.M. (1992). Models for recall and recognition. Annual Review of Psychology, 43, 205-234.

Rapp, A., Ahearne, M., Mathieu, J., \& Schillewaert, N. (2006). The impact of knowledge and empowerment on working smart and working hard: The moderating role of experience. International Journal of Research in Marketing, 23, 279-293.

Rindfleisch, A., Malter, A.J., Ganesan, S., \& Moorman, C. (2008). Cross - sectional versus longitudinal survey research: Concepts, findings, and guidelines. Journal of Marketing Research, 45 (June), 261-279.

Ryan, R.M., \& Deci, E.L. (2000). Self-determination theory and the facilitation of intrinsic motivation, social development and well-being. American Psychologist, 55 (1), 68-78.

Safran, D.G., Kosinski, M., Taira, D.A., Tarlov, A.R., Rogers, W.H., Lieberman, N., \& Ware, J.E. (1998). The primary care assessment survey: tests of data quality and measurement performance. Medical Care, 36 (5), 728-739.

Schwartz, J., Luce, M.F., \& Ariely, D. (2011). Are consumers too trusting? The effects of relationships with expert advisers. Journal of Marketing Research, 48 (Special Issue), S163S174.

Schwartz, S.H. (1992). Universals in the content and structure of values: Theoretical advances and empirical tests in 20 countries," Advances in Experimental Social Psychology, 25, 1-65. 
Schwartz, S.H. (1994). Beyond individualism/collectivism: New dimensions of values. In U. Kim, H. C. Triandis, C. Kagitcibasi, S. C. Choi, \& G. Yoon (Eds.), Individualism and collectivism: Theory, method, and applications. Newbury Park, CA: Sage.

Schwartz, S.H., Melech, G., Lehmann, A., Burgess, S., Harris, M., \& Owens, V. (2001). Extending the cross-cultural validity of the theory of basic human values with a different method of measurement. Journal of Cross-Cultural Psychology, 32(5), 519-542.

Schwartz, S.H. (2006). A theory of cultural value orientations: Explication and applications. Comparative Sociology, 5(2-3), 137-182.

Schwartz, S.H. (2009). Culture matters: National value cultures, sources and consequences. In C.-Y. Chiu, Y.Y. Hong, S. Shavitt, \& R. S. Wyer, Jr. (Eds.), Problems and solutions in cross-cultural theory, research and application. New York: Psychology Press.

Schwartz, S.H. (2011). Studying values: Personal adventure, future directions. Journal of CrossCultural Psychology, 42(2), 307-319.

See, K.E., Morrison, E.W., Rothman, N.B., \& Soll, J.B. (2011). The detrimental effects of power on confidence, advice taking, and accuracy. Organizational Behavior and Human Decision Processes, 116, 272-285.

Sengupta, J., \& Johar, G.V. (2001). Contingent effects of anxiety on message elaboration and persuasion. Personality and Social Psychology Bulletin, 27, 139-150.

Spiegelhalter, D., Best, N.G., Carlin, B.P., \& van der Linde, A. (2002). Bayesian measures of model complexity and fit. Journal of the Royal Statistical Society, 64(4), 583-639.

Starkey, F. (2003). The 'empowerment debate': Consumerist, professional and liberational perspectives in health and social care. Social Policy \& Society, 2:4, pp. 273-284.

Steenkamp, J., \& Baumgartner, H. (1998). Assessing measurement invariance in cross-national consumer research. Journal of Consumer Research, 25(June), 78-90.

Steenkamp, J., \& De Jong, M.G. (2010). A global investigation into the constellation of consumer attitudes toward global and local products. Journal of Marketing, 74 (November), $18-40$.

Steenkamp, J., \& Geyskens (2013). Manufacturer and retailer strategies to impact store brand share: Global integration, local adaptation, and worldwide learning. Marketing Science, in press.

Steenkamp, J., Van Heerde, H.J., \& Geyskens, I. (2010). What makes consumers willing to pay a price premium for national brands over private labels? Journal of Marketing Research, 47 (December), 1011-1024.

Steginga, S.K., \& Occhipinti, S. (2004). The application of hte heuristic-systematic processing model to treatment decision making about prostate cancer. Medical Decision Making, 24(6), 573-583.

Stremersch, S. (2008). Health and marketing: The emergence of a new field of research. International Journal of Research in Marketing, 25, 229-233.

Stremersch, S., Landsman, V., \& Venkataraman, S. (2013). The relationship between DTCA, drug requests, and prescriptions: Uncovering variation in specialty and space. Marketing Science, 32(1), 89-110.

Stremersch, S., \& Lemmens, A. (2009). Sales growth of new pharmaceuticals across the globe: The role of regulatory regimes. Marketing Science, 28(4), 690-708.

Stremersch, S., \& Tellis, G. J. (2004). Managing International Growth of New Products. International Journal of Research in Marketing, 21(4), 421-438. 
Stremersch, S., \& Van Dyck, W. (2009). Marketing of the life sciences: A new framework and research agenda for a nascent field. Journal of Marketing, 73 (July), 4-30.

Stremersch, S., Weiss, A.M., Dellaert, B.G.C., \& Frambach, R.T. (2003). Buying modular systems in technology-intensive markets. Journal of Marketing Research, 40(3), 335-350.

Tanner, M.A., \& Wong, W.H. (1987). The calculation of posterior distributions by data augmentation. Journal of the American Statistical Association, 82 (398), 528-540.

Tellis, G. J., Stremersch, S., \& Yin, E. (2003). The International Takeoff of New Products: The Role of Economics, Culture and Country Innovativeness. Marketing Science, 22(2), 188208.

Tost, L.P., Gino, F., \& Larrick, R.P. (2012). Power, competitiveness, and advice taking: Why the powerful don't listen. Organizational Behavior and Human Decision Processes, 117, 53-65.

Usta, M., \& Häubl, G. (2011). Self-regulatory strength and consumers' relinquishment of decision control: When less effortful decisions are more resource depleting. Journal of Marketing Research, 48 (April), 403-412.

Van den Bulte, C. \& Stremersch, S. (2004). Social contagion and income heterogeneity in new product diffusion: a meta-analytic test. Marketing Science, 23(4), 530-544.

van Everdingen, Y., Fok, D., \& Stremersch, S. (2009). Modeling global spillover of new product takeoff. Journal of Marketing Research, 46(October), 637-652.

Venkataraman, S., \& S. Stremersch (2007). The debate on influencing doctors' decisions: Are drug characteristics the missing link? Management Science, 53(11), 1688-1701.

Vinken, H., Soeters, J., \& Ester, P. (2004). Comparing cultures: Dimensions of culture in a comparative perspective. Leiden, Netherlands: Brill.

Walsh, J.C., Mandalia, S., \& Gazzard, B.G. (2002). Responses to a 1 month self-report on adherence to antiretroviral therapy are consistent with electronic data and virological treatment outcome. AIDS, 16(2), 269-277.

Weinman, J. (1990). Providing written information for patients: Psychological considerations. Journal of the Royal Society of Medicine, 83 (May), 303-305.

Weitlauf, J.C., Cervone, D., Smith, R.E., \& Wright, P.M. (2001). Assessing generalization in perceived self-efficacy: Multidomain and global assessments of the effects of self-defense training for women. Personality and Social Psychology Bulletin, 27 (12), 1683-1691.

World Health Organization (2003). Adherence to long-term therapies-evidence for action. Geneva, Switzerland: World Health Organization.

Wosinska, M. (2005). Direct-to-consumer advertising and drug therapy compliance. Journal of Marketing Research, 42 (August), 323-332.

Yaniv, I. (2004). Receiving other people's advice: Influence and benefit. Organizational Behavior and Human Decision Processes, 93, 1-13.

Yaniv, I., \& Kleinberger, E. (2000). Advice taking in decision making: egocentric discounting and reputation formation. Organizational Behavior and Human Decision Processes, 83(2), 260-281. 


\section{FIGURE 1: A NEW ORGANIZATION OF CUSTOMER-EXPERT DECISION-MAKING MODELS}

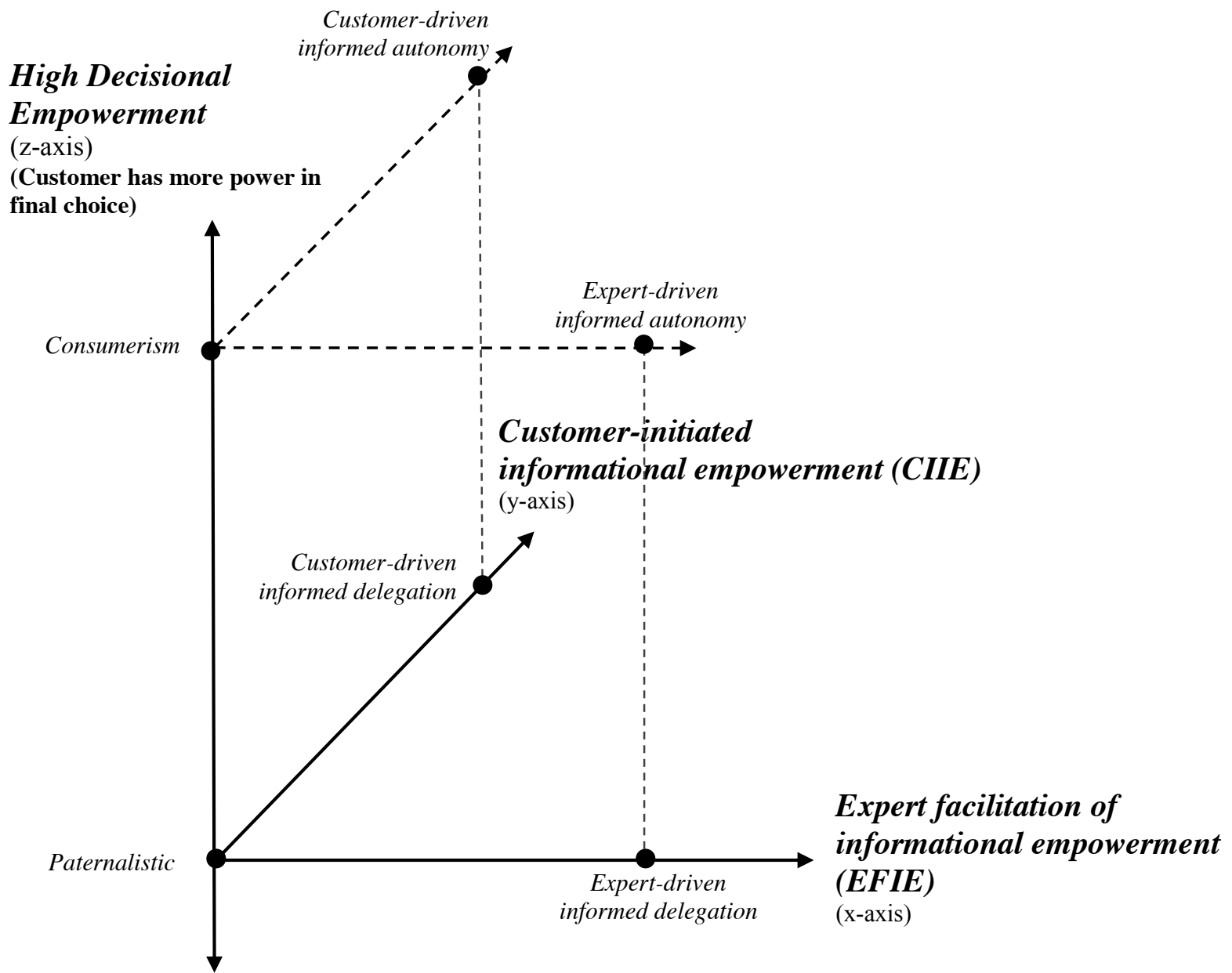

\section{Low Decisional}

Empowerment

(Expert has more power in final choice) 


\section{FIGURE 2: CONCEPTUAL FRAMEWORK}

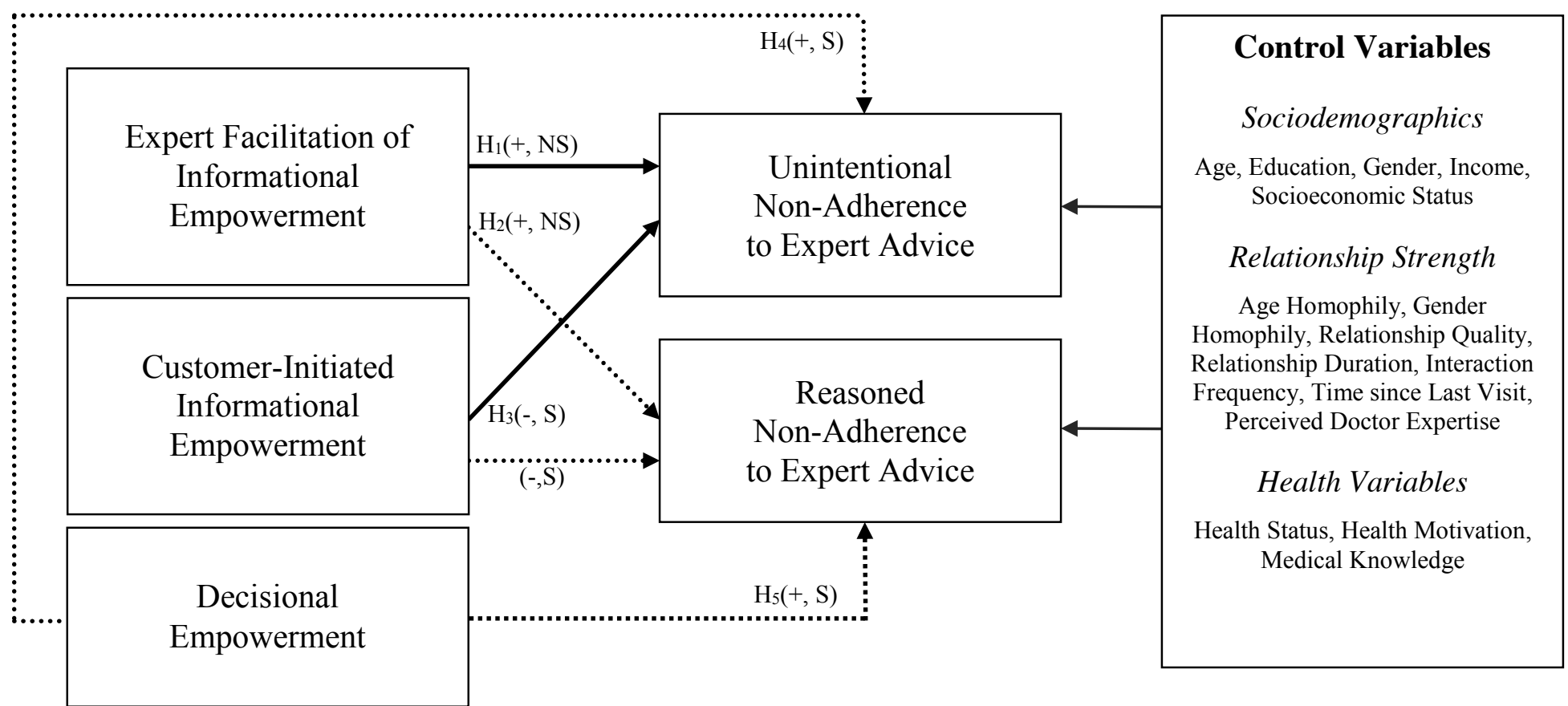

Note: We indicate our hypotheses and expected signs next to the corresponding arrows followed by an indication, in parentheses, of whether or not the corresponding parameter, represents a non-significant (NS; 95\% credible interval of this effect contains zero), or a significant (S; 95\% credible interval of this effect does not contain zero) path. We left the path between customer-initiated informational empowerment and reasoned non-adherence as an open empirical question, so we indicate only our empirical finding. Solid thick arrows indicate hypotheses grounded on dual models of information processing (Chaiken, 1980; Petty \& Cacioppo, 1986). Dotted thick arrows indicate hypotheses grounded on overconfidence (See et al., 2011; Tost, Gino, \& Larrick, 2012). 


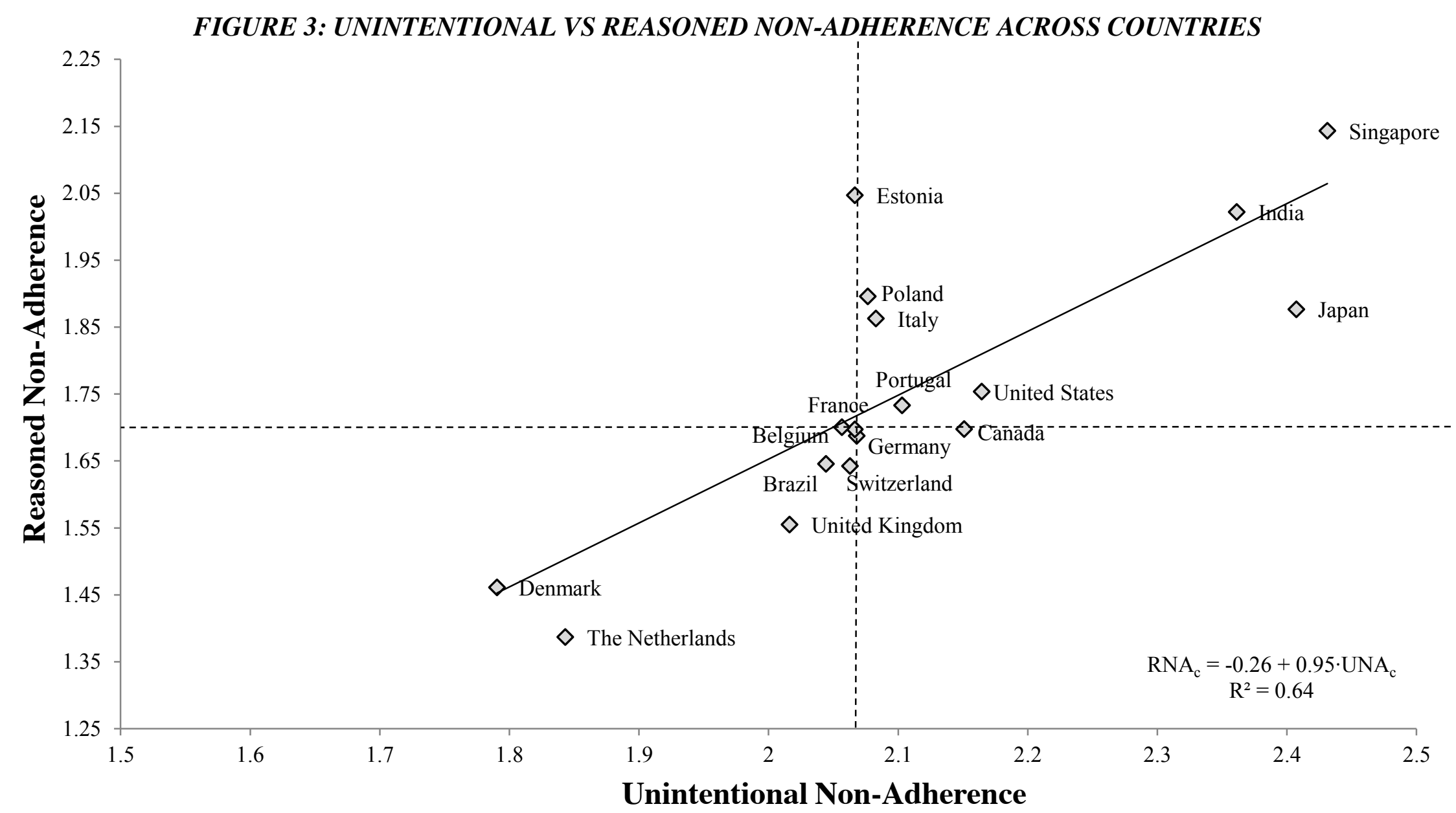

Note: The country-specific levels of unintentional and reasoned non-adherence were computed by averaging, across the MCMC draws, the estimated measurement intercepts $\left(\tau_{i p}^{c}\right)$ of the items measuring each of the constructs. All items were measured in a 5-point Likert scale. The dashed-lines indicate the median levels of unintentional and reasoned non-adherence. The solid line and corresponding equation represent a linear trend model. The $\mathrm{R}^{2}$ of this model is .64 , which indicates a high but not perfect correlation between unintentional and reasoned non-adherence $(\rho=.80)$. 
TABLE 1: EFFECTS OF CUSTOMER EMPOWERMENT ON UNINTENTIONAL AND REASONED NON-ADHERENCE

\begin{tabular}{lccc}
\hline \hline & $\begin{array}{c}\text { Posterior } \\
\text { Cross-Country } \\
\text { Median }\end{array}$ & $\begin{array}{c}\mathbf{9 5 \%} \\
\text { Credible } \\
\text { Interval }\end{array}$ & $\begin{array}{c}\text { Posterior } \\
\text { Cross-Country } \\
\text { Std. Deviation }\end{array}$ \\
\hline $\mathrm{EFIE} \rightarrow$ UNA & .04 & {$[-.01, .09]$} & .13 \\
$\mathrm{EFIE} \rightarrow$ RNA & .04 & {$[-.02, .09]$} & .13 \\
$\mathrm{CIIE} \rightarrow$ UNA & $\mathbf{- . 2 2}$ & {$[-.28,-.17]$} & .15 \\
$\mathrm{CIIE} \rightarrow$ RNA & $\mathbf{- 1 6}$ & {$[-.21,-.11]$} & .17 \\
$\mathrm{DE} \rightarrow$ UNA & $\mathbf{. 0 4}$ & {$[.03, .06]$} & .05 \\
$\mathrm{DE} \rightarrow$ RNA & $\mathbf{. 0 8}$ & {$[.06, .10]$} & .05 \\
\hline
\end{tabular}

Acronyms: EFIE = Expert Facilitation of Informational Empowerment; CIIE = Customer-Initiated Informational Empowerment; DE = Decisional Empowerment; UNA = Unintentional Non-Adherence; $R N A=$ Reasoned Non-Adherence.

Notes: We estimate a random intercept factor analysis model (Maydeu-Olivares \& Coffman, 2006) capturing systematic differences in usage of response scales. At each draw in our MCMC chain, we computed the averages and the standard deviations of the posterior means of the depicted structural paths across all countries in our sample. We stored these cross-country averages (MUs) and standard deviations (SDs). The posterior cross-country medians are the medians of these averages (MUs) across the 1,500 draws we used for inference (total number of draws = 25,000; burn-in =10,000; thinning = 10). The 95\% Credible Intervals depict the $2.5^{\text {th }}$ and the $97.5^{\text {th }}$ percentiles of the distribution of these averages (MUs). We bolded the paths whose $95 \%$ credible interval do not contain zero. The posterior cross-country standard deviations are the medians of the stored standard deviations (SDs). All endogenous and exogenous latent and observed constructs in our structural model have mean zero. 
TABLE 2: CONTROL VARIABLES

\begin{tabular}{|c|c|c|}
\hline Sociodemographics & $\begin{array}{l}\text { Posterior } \\
\text { Median }\end{array}$ & $\begin{array}{c}95 \% \\
\text { Credible } \\
\text { Interval }\end{array}$ \\
\hline Age $\rightarrow$ UNA & -.13 & {$[-.15,-.11]$} \\
\hline Age $\rightarrow$ RNA & -.10 & {$[-.12,-.09]$} \\
\hline Education $\rightarrow$ UNA & -.01 & {$[-.02, .01]$} \\
\hline Education $\rightarrow$ RNA & -.01 & {$[-.03, .00]$} \\
\hline Gender $($ male $=1) \rightarrow$ UNA & .04 & {$[-.01, .09]$} \\
\hline Gender $($ male $=1) \rightarrow$ RNA & .02 & {$[-.03, .07]$} \\
\hline Income $\rightarrow$ UNA & -.00 & {$[-.01, .01]$} \\
\hline Income $\rightarrow$ RNA & -.01 & {$[-.01, .00]$} \\
\hline Socioeconomic status $\rightarrow$ UNA & -.01 & {$[-.02, .01]$} \\
\hline Socioeconomic status $\rightarrow$ RNA & -.01 & {$[-.03, .01]$} \\
\hline \multicolumn{3}{|l|}{ Consumer-Expert Relationship } \\
\hline Relationship quality $\rightarrow$ UNA & -.60 & {$[-.71,-.49]$} \\
\hline Relationship quality $\rightarrow$ RNA & -.72 & {$[-.83,-.61]$} \\
\hline Gender homophily $\rightarrow$ UNA & -.06 & {$[-.11,-.00]$} \\
\hline Gender homophily $\rightarrow$ RNA & -.03 & {$[-.08, .02]$} \\
\hline Age homophily $\rightarrow$ UNA & -.01 & {$[-.02, .01]$} \\
\hline Age homophily $\rightarrow$ RNA & -.00 & {$[-.02, .01]$} \\
\hline Relationship duration $\rightarrow$ UNA & -.03 & {$[-.05,-.02]$} \\
\hline Relationship duration $\rightarrow$ RNA & -.02 & {$[-.04,-.01]$} \\
\hline Interaction frequency $\rightarrow$ UNA & -.01 & {$[-.02, .01]$} \\
\hline Interaction frequency $\rightarrow$ RNA & -.04 & {$[-.05,-.02]$} \\
\hline Time since last visit $\rightarrow$ UNA & .00 & {$[-.01, .02]$} \\
\hline Time since last visit $\rightarrow$ RNA & .02 & {$[.00, .03]$} \\
\hline \multicolumn{3}{|l|}{ Health Drivers } \\
\hline Consumer medical knowledge $\rightarrow$ UNA & -.21 & {$[-.24,-.18]$} \\
\hline Consumer medical knowledge $\rightarrow$ RNA & -.17 & {$[-.20,-.14]$} \\
\hline Health status $\rightarrow$ UNA & -.07 & {$[-.09,-.05]$} \\
\hline Health status $\rightarrow$ RNA & -.02 & {$[-.04, .00]$} \\
\hline Health motivation $\rightarrow$ UNA & -.39 & {$[-.43,-.34]$} \\
\hline Health motivation $\rightarrow$ RNA & -.27 & {$[-.31,-.23]$} \\
\hline Doctor expertise $\rightarrow$ UNA & -.17 & {$[-.25,-.08]$} \\
\hline Doctor expertise $\rightarrow$ RNA & -.26 & {$[-.35,-.18]$} \\
\hline
\end{tabular}

Acronyms: EFIE = Expert Facilitation of Informational Empowerment; CIIE = Customer-Initiated Informational Empowerment $; D E=$ Decisional Empowerment; UNA = Unintentional Non-Adherence $; R N A=$ Reasoned NonAdherence.

Note: For model stability and identification, the structural paths for control variables were estimated pooled across countries. 
TABLE 3: RANDOM INTERCEPTS MEDIATION MODEL

\begin{tabular}{|c|c|c|c|}
\hline Effects of the Mediators on Non-Adherence & $\begin{array}{l}\text { Posterior } \\
\text { Cross- } \\
\text { Country } \\
\text { Median }\end{array}$ & $\begin{array}{c}95 \% \\
\text { Credible } \\
\text { Interval }\end{array}$ & $\begin{array}{c}\text { Posterior } \\
\text { Cross- } \\
\text { Country Std. } \\
\text { Deviation }\end{array}$ \\
\hline Communication Quality $\rightarrow$ UNA & -.26 & {$[-.31,-.22]$} & .15 \\
\hline Communication Quality $\rightarrow$ RNA & -.29 & {$[-.34,-.25]$} & .19 \\
\hline Health Locus of Control $\rightarrow$ UNA & .03 & {$[.02, .05]$} & .06 \\
\hline Health Locus of Control $\rightarrow$ RNA & .09 & {$[.07, .11]$} & .06 \\
\hline \multicolumn{4}{|l|}{ Effects of Empowerment on the Mediators } \\
\hline EFIE $\rightarrow$ Communication Quality & .67 & {$[.64, .70]$} & .15 \\
\hline EFIE $\rightarrow$ Health Locus of Control & -.05 & {$[-.12, .02]$} & .22 \\
\hline CIIE $\rightarrow$ Communication Quality & -.06 & {$[-.10,-.03]$} & .19 \\
\hline CIIE $\rightarrow$ Health Locus of Control & .24 & {$[.15, .31]$} & .28 \\
\hline $\mathrm{DE} \rightarrow$ Communication Quality & -.03 & {$[-.04,-.02]$} & .03 \\
\hline $\mathrm{DE} \rightarrow$ Health Locus of Control & .11 & {$[.04, .16]$} & .14 \\
\hline \multicolumn{4}{|l|}{ Direct Effects } \\
\hline $\mathrm{EFIE} \rightarrow \mathrm{UNA}$ & .25 & {$[.18, .31]$} & .16 \\
\hline $\mathrm{EFIE} \rightarrow \mathrm{RNA}$ & .25 & {$[.20, .31]$} & .15 \\
\hline $\mathrm{CIIE} \rightarrow \mathrm{UNA}$ & -.23 & {$[-.29,-.18]$} & .16 \\
\hline $\mathrm{CIIE} \rightarrow \mathrm{RNA}$ & -.16 & {$[-.22,-.11]$} & .17 \\
\hline $\mathrm{DE} \rightarrow \mathrm{UNA}$ & .04 & {$[.02, .05]$} & .05 \\
\hline $\mathrm{DE} \rightarrow \mathrm{RNA}$ & .07 & {$[.05, .08]$} & .06 \\
\hline
\end{tabular}

Acronyms: EFIE = Expert Facilitation of Informational Empowerment CIIE $=$ Customer-Initiated Informational Empowerment $; D E=$ Decisional Empowerment $; U N A=$ Unintentional Non-Adherence $; R N A=$ Reasoned NonAdherence.

Note: The model includes the same set of control variables used in our main model. The full set of parameter estimates is available upon request. 
TABLE 4 - POSTERIOR CORRELATIONS: SCHWARTZ'S CULTURAL DIMENSIONS AND THE RELATIONSHIP BETWEEN CUSTOMER EMPOWERMENT AND NON-ADHERENCE

\begin{tabular}{|c|c|c|c|c|c|c|c|c|c|c|c|c|c|c|}
\hline $\mathrm{EFIE} \rightarrow \mathrm{UNA}$ & .01 & {$[-.31 ; .31]$} & .14 & {$[-.21 ; .45]$} & -.14 & {$[-.45 ; .22]$} & .18 & {$[-.20 ; .48]$} & -.45 & {$[-.71 ;-.08]$} & .25 & {$[-.06 ; .53]$} & -.30 & {$[-.61 ; .09]$} \\
\hline $\mathrm{CIIE} \rightarrow \mathrm{UNA}$ & .32 & {$[-.01 ; .60]$} & .35 & {$[-.03 ; .65]$} & -.34 & {$[-.65 ; .03]$} & .08 & {$[-.28 ; .41]$} & -.03 & {$[-.39 ; .37]$} & .11 & {$[-.21 ; .44]$} & -.14 & {$[-.50 ; .28]$} \\
\hline $\mathrm{CIIE} \rightarrow \mathrm{RNA}$ & .40 & {$[.13 ; .64]$} & .35 & {$[.03 ; .59]$} & -.43 & {$[-.66 ;-.11]$} & .22 & {$[-.09 ; .50]$} & -.17 & {$[-.45 ; .18]$} & .15 & {$[-.12 ; .40]$} & -.24 & {$[-.54 ; .11]$} \\
\hline $\mathrm{DE} \rightarrow \mathrm{UNA}$ & .16 & {$[-.18 ; .49]$} & .30 & {$[-.04 ; .59]$} & -.25 & {$[-.55 ; .09]$} & .07 & {$[-.28 ; .43]$} & .00 & {$[-.36 ; .34]$} & .36 & {$[.05 ; .62]$} & -.01 & {$[-.40 ; .37]$} \\
\hline
\end{tabular}

Acronyms: EFIE = Expert Facilitation of Informational Empowerment ; CIIE = Customer-Initiated Informational Empowerment; DE = Decisional

Empowerment; $U N A=$ Unintentional Non-Adherence; $R N A=$ Reasoned Non-Adherence. 


\title{
APPENDIX: MEASURES AND METRIC INVARIANCE
}

TABLE A1: CONSTRUCTS AND MEASURES

\author{
Constructs and Measures [Source] \\ Unintentional Non-Adherence $(\boldsymbol{\alpha}=\mathbf{~ . 8 4})$ [DiMatteo et al. (1993)]: Please tell us how often you can imagine \\ yourself ... \\ 1. ...forgetting to take your medicines? \\ 2. ...having a hard time doing what your doctor suggested you to do? \\ 3. ...being unable to do what was necessary to follow your doctor's treatment plans? \\ 4. ...missing taking your medications because you were away from home or busy with other things?
}

Reasoned Non-Adherence $(\boldsymbol{\alpha}=\mathbf{. 8 7})$ [DiMatteo et al. (1993)]: Please tell us how often you can imagine yourself missing taking your medications because...

1. ... you seemed to need less medicine?

2. ... you didn't believe in the treatment your doctor was recommending you?

3. ... you wanted to avoid side effects or felt like the drug was toxic or harmful?

4. ... you wanted to try alternative therapies (e.g. herbalist, homeopathic or acupuncture treatments...)?

5. ...the medication was too expensive?

Response scale for non-adherence: 1 = "never," 2 = "rarely," 3 = "sometimes," 4 = "often," 5 = "very often"

Expert Facilitation of Informational Empowerment $(\boldsymbol{\alpha}=\mathbf{. 8 3})$ [Kao et al. (1998); Lerman et al. (1990)]: Please

read each of the statements below and indicate to what extent it describes your own experience with your doctor.

1. My doctor asks me about how my family or living situation might affect my health.

2. My doctor shares with me the risks and benefits associated with alternative treatment options.

3. My doctor asks me what I believe is causing my medical symptoms.

4. My doctor encourages me to give my opinion about medical treatments.

Customer-Initiated Informational Empowerment $(\alpha=.74)$ [Lerman et al. (1990)]: Please read each of the

statements below and indicate to what extent it describes your own experience with your doctor.

1. I ask my doctor to explain to me the treatments or procedures in detail.

2. I ask my doctor a lot of questions about my medical symptoms.

3. I give my opinion (agreement or disagreement) about the types of test or treatment that my doctor orders. Response scale for informational empowerment: 1 = "strongly disagree," 2 = "disagree," 3 = "neutral," 4 = "agree," $5=$ "strongly agree"

Decisional Empowerment [Similar to Usta and Häubl (2011)]: Who possesses more power in treatment decisions, that is, who has more influence in determining the treatment(s) you follow?

Response scale: 1 = "my doctor has more power," 2 = "my doctor has slightly more power," 3 = "my doctor and I have about the same power," 4 = "I have slightly more power," 5 = "I have more power".

Communication Quality $(\boldsymbol{\alpha}=\mathbf{. 8 9})$ [Kao et al. (1998)]: Please read each of the statements below and indicate to what extent it describes your own experience with your doctor.

1. When I ask questions to my doctor, I get answers that are understandable.

2. My doctor gives me enough time to explain the reasons for my visit.

3. My doctor takes enough time to answer my questions.

Response scale: 1 = "strongly disagree," 2 = "disagree," 3 = "neutral," 4 = "agree," 5 = "strongly agree"

Health Locus of Control [Item from Moorman and Matulich (1993)]:

I have a lot of confidence in my ability to cure myself once I get sick.

Response scale: 1 = "strongly disagree," 2 = "disagree," 3 = "neutral," 4 = "agree," 5 = "strongly agree" 
TABLE A1 (Cont.): CONSTRUCTS AND MEASURES

Constructs and Measures [Source]

Age: We use the standardized score of age.

Education: $1=$ "no formal education," 2 = "education up to age 12," 3 = "education up to age 14," 4 = "education up to age $18, " 5$ = "higher education," 6 = "university".

Gender: $0=$ "female," 1 = "male"

Income*: 1 = "up to $[\$ 2,000]$ per year," $2=$ "between $[\$ 2,000]$ and $[\$ 4,999]$ per year," 3 = "between $[\$ 5,000]$ and $[\$ 9,999]$ per year," $4=$ "between $[\$ 10,000]$ and $[\$ 19,999]$ per year," $5=$ "between $[\$ 20,000]$ and $[\$ 39,999]$ per year," 6 = "between $[\$ 40,000]$ and $[\$ 74,999], " 7=$ "more than $[\$ 75,000]$ per year"

*Note: Income levels were converted into the currency of each country.

Socioeconomic Status [Steenkamp, Van Heerde, \& Geyskens (2010)]: If people in our society are divided into upper, upper middle, middle, lower middle, working, and lower classes, which class do you think you belong to? Response scale: 1 = "lower class," 2 = "working class," 3 = "lower middle class," 4 = "middle class," 5 = "upper middle class," 6 = "upper class".

Relationship Quality $(\boldsymbol{\alpha}=\mathbf{. 8 3})$ [Kao et al. (1998); Morgan \& Hunt (1994)]

Please read each of the statements below and indicate to what extent it describes your own experience with your doctor.

1. I trust that my doctor keeps personally sensitive medical information private.

2. I trust my doctor's judgment about my medical care.

3. I trust that my doctor performs necessary medical tests and procedures regardless of cost.

4. I trust that my doctor performs only medically necessary tests and procedures.

5. The relationship I have with my doctor is something I am very committed to.

6. The relationship I have with my doctor is something I intend to maintain indefinitely.

Response scale: 1 = "strongly disagree," 2 = "disagree," 3 = "neutral," 4 = "agree," 5 = "strongly agree"

Age Homophily [Own Development]: $-1 *$ [ Standardized score of the difference, in absolute value, between the patient and the physician's age]

Gender Homophily [Own Development]: $1=$ patient and physician of the same gender, and $0=$ otherwise

Relationship Duration [Own Development]: Standardized score of the relationship duration in years.

Interaction Frequency [Own Development]: How regularly do you visit your doctor?

Response scale: 1 = "usually less than once every two years ," 2 = "at least once every two years, , 3 = "at least once

a year," 4 = "usually once every six months," 5 = "once every three months," 6 = "once every month,"7 = "every other week," 8 = "once a week or more".

Time Since Last Visit [Own Development]: When was your last visit to your doctor?

Response scale: 1 = "less than one month ago," 2 = "one to three months ago," 3 = "four to six months ago," $4=$ "seven months to one year ago," $5=$ "more than one year ago".

Consumer Medical Knowledge $(\rho=.77)$ [Stremersch et al. $(2003)$ ]: Regarding medical treatment of diseases you consider yourself...

1. 1 = "not at all knowledgeable," to 5 = "very knowledgeable"

2. $1=$ "not at all experienced," to $5=$ "very experienced"

Health Status [PCAS; Safran et al. (1998)]: In general, would you say your health is...

1 = "poor," 2 = "fair," 3 = "good," 4 = "very good," 5 = "excellent".

Health Motivation $(\boldsymbol{\rho}=\mathbf{. 6 0})$ [Moorman \& Matulich (1993)]: Please read each of the statements below and indicate

how much you agree with each of them:

1. I try to prevent health problems before I feel any symptoms.

2. I try to protect myself against health hazards I hear about.

Response scale: 1 = "strongly disagree," 2 = "disagree," 3 = "neutral," 4 = "agree," 5 = "strongly agree"

Perceived Doctor Expertise $(\boldsymbol{\rho}=\mathbf{. 8 2})$ [Brown et al. $(1995)$ ]: Please read each of the statements below and indicate

to what extent it describes your own experience with your doctor.

1. My doctor is very competent and well-trained.

2. I usually get good advice from my doctor.

Response scale: 1 = "strongly disagree," 2 = "disagree," 3 = "neutral," 4 = "agree," 5 = "strongly agree" 
TABLE A2: SCALE RELIABILITIES PER COUNTRY

\begin{tabular}{|c|c|c|c|c|c|c|c|c|c|c|}
\hline Country & $\mathbf{N}$ & UNA* & RNA* & EIFE* & CIIE* & $\mathbf{Q C *}$ & $\mathbf{R} \mathbf{Q}^{*}$ & CMK** & HM** & $\mathrm{PDE}^{* *}$ \\
\hline Belgium & 669 & .815 & .817 & .803 & .703 & .898 & .782 & .774 & .628 & .807 \\
\hline Canada & 540 & .830 & .871 & .841 & .721 & .896 & .881 & .788 & .550 & .843 \\
\hline Denmark & 570 & .777 & .828 & .830 & .754 & .916 & .829 & .752 & .624 & .777 \\
\hline Estonia & 523 & .792 & .778 & .842 & .660 & .839 & .807 & .779 & .575 & .765 \\
\hline France & 776 & .775 & .820 & .823 & .711 & .875 & .818 & .672 & .442 & .842 \\
\hline Germany & 783 & .824 & .872 & .888 & .753 & .926 & .822 & .911 & .595 & .809 \\
\hline India & 521 & .853 & .909 & .824 & .706 & .817 & .850 & .640 & .547 & .810 \\
\hline Italy & 818 & .862 & .853 & .842 & .724 & .897 & .876 & .722 & .528 & .830 \\
\hline Japan & 758 & .846 & .900 & .770 & .819 & .830 & .828 & .645 & .659 & .691 \\
\hline Poland & 760 & .873 & .873 & .840 & .721 & .916 & .775 & .830 & .755 & .816 \\
\hline Singapore & 815 & .895 & .880 & .803 & .701 & .898 & .865 & .761 & .677 & .844 \\
\hline Switzerland & 547 & .785 & .837 & .821 & .716 & .877 & .786 & .757 & .549 & .796 \\
\hline The Netherlands & 795 & .766 & .820 & .812 & .770 & .900 & .851 & .717 & .625 & .826 \\
\hline United Kingdom & 781 & .840 & .870 & .841 & .726 & .903 & .879 & .785 & .532 & .845 \\
\hline United States & 770 & .824 & .889 & .816 & .728 & .900 & .869 & .784 & .660 & .828 \\
\hline \multirow[t]{2}{*}{ Pooled } & 11,735 & .844 & .870 & .833 & .736 & .892 & .833 & .765 & .595 & .822 \\
\hline & Ir Items: & 4 & 5 & 4 & 3 & 3 & 6 & 2 & 2 & 2 \\
\hline
\end{tabular}

Acronyms: UNA = Unintentional Non-Adherence; RNA = Reasoned Non-Adherence. EFIE = Expert Facilitation of Informational Empowerment CIIE = Customer-Initiated Informational Empowerment; DE = Decisional Empowerment. $Q C=$ Communication Quality. RQ $=$ Relationship Quality. CMK = Consumer Medical Knowledge. HM = Health Motivation. PDE = Perceived Doctor Expertise.

* For multi-item scales with more than two items we report Cronbach's alpha as our measure of scale reliability.

** For two-item scales we report Pearson's correlation coefficient as our measure of scale reliability. 


\section{TABLE A3: CROSS-COUNTRY COMPARISON OF FACTOR LOADINGS BETWEEN METRIC INVARIANCE AND CONFIGURAL MODELS}

\begin{tabular}{lc}
\hline \hline Country & $\begin{array}{c}\text { Percentage of Loadings in the Metric } \\
\text { Invariance within the } \\
\text { CI of the Configural Model }\end{array}$ \\
\hline Belgium & $80 \%$ \\
Brazil & $85 \%$ \\
Canada & $85 \%$ \\
Denmark & $50 \%$ \\
Estonia & $70 \%$ \\
France & $75 \%$ \\
Germany & $70 \%$ \\
India & $70 \%$ \\
Italy & $75 \%$ \\
Japan & $65 \%$ \\
Poland & $55 \%$ \\
Portugal & $80 \%$ \\
Singapore & $50 \%$ \\
Switzerland & $75 \%$ \\
The Netherlands & $70 \%$ \\
United Kingdom & $80 \%$ \\
United States & $80 \%$ \\
\hline
\end{tabular}


TABLE A4 (PATt 1 of 2): COUNTRY-SPECIFIC DESCRIPTIVE STATISTICS

\begin{tabular}{|c|c|c|c|c|c|c|}
\hline \multirow{2}{*}{ Construct } & \multicolumn{2}{|c|}{ Belgium } & \multicolumn{2}{|c|}{ Brazil } & \multicolumn{2}{|c|}{ Canada } \\
\hline & Mean & SD & Mean & SD & Mean & SD \\
\hline UNA & 2.00 & .67 & 2.03 & .77 & 2.12 & .67 \\
\hline RNA & 1.63 & .66 & 1.65 & .73 & 1.68 & .74 \\
\hline EFIE & 3.70 & .72 & 3.96 & .73 & 3.55 & .84 \\
\hline CIIE & 3.80 & .68 & 3.99 & .70 & 3.73 & .69 \\
\hline $\mathrm{DE}$ & 2.01 & .99 & 1.86 & 1.03 & 2.24 & 1.05 \\
\hline Relationship Quality & 4.07 & .52 & 4.08 & .58 & 3.98 & .66 \\
\hline Consumer Medical Knowledge & 3.34 & .89 & 3.31 & 1.07 & 3.29 & .91 \\
\hline Health Motivation & 3.54 & .81 & 3.89 & .85 & 3.84 & .68 \\
\hline Doctor Expertise & 4.37 & .56 & 4.53 & .54 & 4.26 & .68 \\
\hline \multirow{2}{*}{ Construct } & \multicolumn{2}{|c|}{ Denmark } & \multicolumn{2}{|c|}{ Estonia } & \multicolumn{2}{|c|}{ France } \\
\hline & Mean & SD & Mean & SD & Mean & SD \\
\hline UNA & 1.75 & .56 & 2.11 & .60 & 2.03 & .68 \\
\hline RNA & 1.43 & .56 & 2.09 & .75 & 1.61 & .66 \\
\hline EFIE & 3.36 & .87 & 3.08 & .91 & 3.61 & .80 \\
\hline CIIE & 3.82 & .73 & 3.37 & .73 & 3.71 & .75 \\
\hline $\mathrm{DE}$ & 1.91 & 1.04 & 1.94 & .99 & 1.64 & .89 \\
\hline Relationship Quality & 3.91 & .59 & 3.93 & .58 & 4.00 & .57 \\
\hline Consumer Medical Knowledge & 3.37 & .90 & 2.93 & .90 & 3.52 & .86 \\
\hline Health Motivation & 3.48 & .85 & 3.67 & .87 & 3.47 & .82 \\
\hline Doctor Expertise & 4.26 & .67 & 3.91 & .76 & 4.29 & .68 \\
\hline \multirow{2}{*}{ Construct } & \multicolumn{2}{|c|}{ Germany } & \multicolumn{2}{|c|}{ India } & \multicolumn{2}{|c|}{ Italy } \\
\hline & Mean & SD & Mean & SD & Mean & SD \\
\hline UNA & 2.06 & .67 & 2.41 & .79 & 2.06 & .75 \\
\hline RNA & 1.67 & .73 & 2.07 & .90 & 1.83 & .78 \\
\hline EFIE & 3.70 & .90 & 3.70 & .73 & 3.40 & .86 \\
\hline CIIE & 3.83 & .73 & 3.65 & .70 & 3.76 & .72 \\
\hline $\mathrm{DE}$ & 2.09 & 1.01 & 1.79 & .92 & 2.02 & 1.01 \\
\hline Relationship Quality & 4.00 & .61 & 3.92 & .60 & 3.71 & .70 \\
\hline Consumer Medical Knowledge & 3.33 & .93 & 3.38 & .90 & 3.58 & .81 \\
\hline Health Motivation & 3.46 & .79 & 3.95 & .73 & 3.64 & .78 \\
\hline Doctor Expertise & 4.31 & .68 & 4.24 & .68 & 3.91 & .80 \\
\hline
\end{tabular}

Acronyms: UNA = Unintentional Non-Adherence; $R N A=$ Reasoned Non-Adherence $;$ EFIE $=$ Expert Facilitation of Informational Empowerment; $C I I E=$ Customer-Initiated Informational Empowerment; DE = Decisional Empowerment. 
TABLE A4 (PArt 2 of 2): COUNTRY-SPECIFIC DESCRIPTIVE STATISTICS

\begin{tabular}{|c|c|c|c|c|c|c|}
\hline \multirow{2}{*}{ Construct } & \multicolumn{2}{|c|}{ Japan } & \multicolumn{2}{|c|}{ The Netherlands } & \multicolumn{2}{|c|}{ Poland } \\
\hline & Mean & SD & Mean & SD & Mean & SD \\
\hline UNA & 2.39 & .64 & 1.85 & .61 & 2.12 & .74 \\
\hline RNA & 1.81 & .74 & 1.42 & .57 & 1.90 & .76 \\
\hline EFIE & 3.45 & .63 & 3.51 & .75 & 3.46 & .86 \\
\hline CIIE & 3.42 & .71 & 3.53 & .72 & 3.56 & .75 \\
\hline $\mathrm{DE}$ & 1.85 & .77 & 2.35 & 1.03 & 1.62 & 1.00 \\
\hline Relationship Quality & 3.65 & .51 & 3.87 & .57 & 3.67 & .62 \\
\hline Consumer Medical Knowledge & 3.22 & .90 & 3.29 & .88 & 3.28 & 1.02 \\
\hline Health Motivation & 3.49 & .75 & 3.46 & .74 & 3.76 & .91 \\
\hline Doctor Expertise & 3.71 & .67 & 4.11 & .68 & 4.07 & .74 \\
\hline \multirow{2}{*}{ Construct } & \multicolumn{2}{|c|}{ Portugal } & \multicolumn{2}{|c|}{ Singapore } & \multicolumn{2}{|c|}{ Switzerland } \\
\hline & Mean & SD & Mean & SD & Mean & SD \\
\hline UNA & 2.12 & .73 & 2.49 & .71 & 2.04 & .62 \\
\hline RNA & 1.75 & .70 & 2.20 & .74 & 1.67 & .66 \\
\hline EFIE & 3.71 & .81 & 3.58 & .63 & 3.83 & .77 \\
\hline CIIE & 3.97 & .63 & 3.64 & .59 & 3.96 & .66 \\
\hline $\mathrm{DE}$ & 1.85 & 1.00 & 2.20 & 1.01 & 2.28 & 1.00 \\
\hline Relationship Quality & 3.86 & .66 & 3.75 & .51 & 4.05 & .55 \\
\hline Consumer Medical Knowledge & 3.29 & .83 & 3.04 & .76 & 3.49 & .83 \\
\hline Health Motivation & 3.86 & .74 & 3.93 & .65 & 3.58 & .80 \\
\hline Doctor Expertise & 4.23 & .68 & 4.03 & .60 & 4.38 & .60 \\
\hline \multirow{2}{*}{ Construct } & \multicolumn{2}{|c|}{ United Kingdom } & \multicolumn{2}{|c|}{ United States } & & \\
\hline & Mean & SD & Mean & SD & & \\
\hline UNA & 1.96 & .70 & 2.11 & .74 & & \\
\hline RNA & 1.50 & .67 & 1.74 & .80 & & \\
\hline EFIE & 3.49 & .84 & 3.72 & .78 & & \\
\hline CIIE & 3.60 & .71 & 3.89 & .68 & & \\
\hline $\mathrm{DE}$ & 1.91 & .99 & 2.48 & 1.11 & & \\
\hline Relationship Quality & 3.98 & .64 & 4.09 & .61 & & \\
\hline Consumer Medical Knowledge & 3.34 & .93 & 3.50 & .90 & & \\
\hline Health Motivation & 3.70 & .71 & 3.92 & .71 & & \\
\hline Doctor Expertise & 4.33 & .68 & 4.38 & .65 & & \\
\hline
\end{tabular}

Acronyms: UNA = Unintentional Non-Adherence; $R N A=$ Reasoned Non-Adherence; EFIE $=$ Expert Facilitation of Informational Empowerment; $C I I E=$ Customer-Initiated Informational Empowerment; DE = Decisional

Empowerment. 


\begin{tabular}{|c|c|}
\hline \multicolumn{2}{|c|}{ ERIM Report Series Research in Management } \\
\hline ERIM Report Series reference number & ERS-2014-005-MKT \\
\hline Date of publication & $2014-03-31$ \\
\hline Version & $31-03-2014$ \\
\hline Number of pages & 58 \\
\hline Persistent URL for paper & http://hdl.handle.net/1765/50909 \\
\hline Email address corresponding author & camacho@ese.eur.nl \\
\hline Address & $\begin{array}{l}\text { Erasmus Research Institute of Management } \\
\text { (ERIM) } \\
\text { RSM Erasmus University / Erasmus School } \\
\text { of Economics } \\
\text { Erasmus University Rotterdam } \\
\text { PO Box } 1738 \\
3000 \text { DR Rotterdam, The Netherlands } \\
\text { Phone: +31104081182 } \\
\text { Fax: +31104089640 } \\
\text { Email: info@erim.eur.nl } \\
\text { Internet: http://www.erim.eur.nl }\end{array}$ \\
\hline Availability & 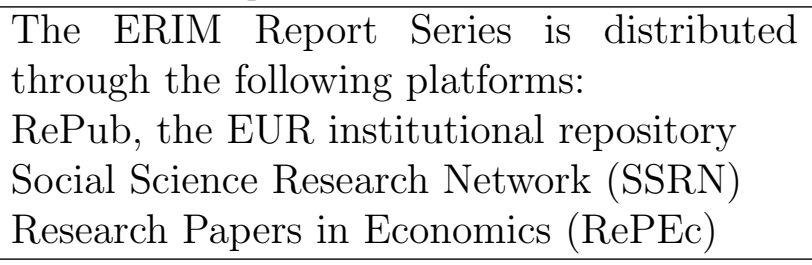 \\
\hline Classifications & $\begin{array}{l}\text { The electronic versions of the papers in the } \\
\text { ERIM Report Series contain bibliographic } \\
\text { metadata from the following classification } \\
\text { systems: } \\
\text { Library of Congress Classification (LCC) } \\
\text { Journal of Economic Literature (JEL) } \\
\text { ACM Computing Classification System } \\
\text { Inspec Classification Scheme (ICS) }\end{array}$ \\
\hline
\end{tabular}

